\title{
Experimental and numerical investigations of axially loaded RC walls restrained on three sides
}

\author{
Nhat-Minh Ho and Jeung-Hwan Doh*
}

School of Engineering, Griffith University Gold Coast Campus, Queensland 4222, Australia

\begin{abstract}
SUMMARY
Axially loaded reinforced concrete (RC) walls in tilt-up structures can be supported top and bottom only by floors or roof structures. However, RC walls are often combined to form I-, C-, T- and Lshapes to make efficient use of the building area in multi-storey buildings. With these configurations, walls may also be laterally supported on either or both sides by interconnecting walls. While many researchers have investigated the behaviours of RC walls, either in one-way action or two-way action supported on four sides with and without openings, limited research has been conducted on two-way action walls supported on three sides (TW3S). As such, this paper experimentally and numerically investigates the behaviour of TW3S walls. Details of the twelve half-scale walls tested, including experimental setup, failure loads, crack patterns and load-deflection characteristics, are reported. In addition, the Finite Element Method using ABAQUS software for investigating the behaviour of TW3S walls is described in detail. Finally, due to the conservative nature of code design equations and there being limited available methods for predicting the ultimate load of TW3S walls with openings, a rigid-plastic approach has been proposed in this study to evaluate the failure load of TW3S walls.
\end{abstract}

KEY WORDS: concrete walls; openings; slenderness ratio; aspect ratio; axial load; yield line.

\footnotetext{
* Correspondence to: Jeung-Hwan Doh, School of Engineering, Griffith University, Gold Coast, QLD 4222, Australia. E-mail: j.doh@griffith.edu.au
} 


\section{INTRODUCTION}

Reinforced concrete (RC) walls have been commonly used as load-bearing elements in buildings and offshore structures. Primary applications include tilt-up precast structures, shear walls in multi-storeyed buildings, lift core walls in high-rise buildings, components in bridge construction such as webs of beams or box girders, storage cells in offshore concrete structures, and parts of floating concrete structures such as barges and pontoons [1]. In general, typical loadings on RC walls are in-plane loads, consisting of gravitational and shear forces, as well as out-of-plane transverse loads. In-plane vertical loads are frequently eccentric, causing a pronounced out-of-plane curvature owing to a range of loading conditions including corbel elements applied to the wall face, imperfections in construction, uneven loading being experienced on top of the wall and temporary loading during operation and/or maintenance [2]. Walls can be constructed with various support conditions. Walls restrained top and bottom only by floor plates, with free vertical edges, are usually encountered in tilt-up concrete structures. Such walls behave in one-way (OW) action depicted by uniaxial curvature in the direction of loading, as shown in Figure 1(a). In practice, walls behaving in two-way action supported on three sides (TW3S) and supported on four sides (TW4S), provided by floor plates and stiffening walls, or other sufficiently stiff members, are usually encountered in monolithic concrete structures, particularly in core walls of tall buildings. These panels generally deform along both the horizontal and vertical directions, as outlined in Figures 1(b-c). As a result of architectural requirements and/or functional modifications of the structures, provision of openings for doors and windows or paths for ventilation systems is unavoidable (Figures 1(d-f)). These openings can be divided into three types, namely already existing openings, existing openings that have been enlarged and newly created openings [3]. Creating or modifying openings in a wall affects the stress distribution within that wall. Seddon [4] concluded that openings are a source of weakness and can size-dependently reduce the structure's stiffness and load bearing capacity. The structural effect of small openings is often negligible due to the ability of RC walls to 
redistribute stresses, while large openings in $\mathrm{RC}$ walls cause the disturbance in the stress path which significantly alters the static system [5].

Despite there being many experimental and numerical studies on the behaviour of RC walls, the performance of TW3S walls with and without openings has not been thoroughly addressed. The few studies that have been published in this area $[2,6,7]$ were reviewed in Section 2 of this manuscript, indicating that more investigation is needed. This research, therefore, experimentally and numerically investigates the behaviour of axially loaded TW3S walls with and without openings. Details of the walls tested, including experimental setup and loading regime, failure loads, typical crack patterns and load-deflection characteristics, are provided in this manuscript. The Finite Element Method (FEM) using ABAQUS software for investigating the behaviour of TW3S walls is described in this study as well. Moreover, due to the limited and conservative approach of current design guidelines on evaluating the failure loads of TW3S walls with and without openings as also highlighted in this manuscript, the provision of a method with broader applicability is a necessary requirement for engineering application. In this study, an attempt was thus proposed to incorporate the rigid-plastic approach developed by Popescu et al. [8] into ultimate load prediction of TW3S walls. The approach provided good agreement with the test data in this study and other published test results.

\section{REVIEW OF THE DESIGN AND RESEARCH ON AXIALLY LOADED WALLS}

At present, many national standards devote separate chapters to wall design. In general, two contemporary design methods can be compiled: (1) the equivalent column design procedure; and (2) the use of simplified or empirically derived equations. The former is arguably the more rational approach; however, Robinson et al. [9] and Huang et al. [10] verified the unsuitability of this method for predicting the buckling capacity of minimally, centrally RC panels. The American Concrete Institute Code (ACI318-14) [11] provides simplified wall design equations intended for OW load bearing walls only. On the other hand, Eurocode 2 (EC2-04) [12] and the 
Australian Standard (AS3600-09) [13] acknowledge the increased strength effects of side restraints, providing guidelines by way of effective height factors for walls with various support conditions. Popescu et al. [3] and Ho et al. [14] demonstrated that all these national codes of practice provide too conservative predictions of axial load capacities. In addition, the design of walls with the presence of openings is given little guidance in the code of standards. The ultimate design axial strength of a braced wall is given by the formulae shown in Table 1 .

where $\phi$ is the capacity reduction factor, in which $\phi=0.65$ for ACI318 [11], $\phi=0.67$ for EC2 [12] ( $\phi=1 / \gamma c$, where $\gamma c$ is a partial safety factor, and equal to 1.5 for the ultimate limit state in the case of concrete under axial load) and $\phi=0.6$ for AS3600 [13]; $t_{w}$ is the wall thickness; $L_{w}$ is the horizontal length; $e$ is the load eccentricity; $f^{\prime}{ }_{c}$ is the compressive concrete strength; and $e_{a}$ is the additional eccentricity due to the deformation of the wall, in which $e_{a}=H_{w e} / 400$ for EC2 [12] and $e_{a}=H_{w e}{ }^{2} /\left(2500 t_{w}\right)$ for AS3600 [13]. Regarding both European [12] and Australian [13] models, the effective height shall be taken as $H_{w e}=k H_{w}$ in which the factor $k$ is determined for various support conditions as follows: for OW walls, $k=1$, when walls are not restrained against rotation at one or both ends; for TW3S walls, $k=1 /\left(1+\left(H_{w} / 3 L_{w}\right)^{2}\right)$ for EC2 [12], but the value of $k$ is not less than 0.3 for AS3600 [13]; for TW4S walls, $k=1 /\left(1+\left(H_{w} / L_{w}\right)^{2}\right)$ when $H_{w} \leq$ $L_{w}$ or $k=L_{w} / 2 H_{w}$ when $H_{w}>L_{w} . H_{w}$ is the floor-to-floor unsupported height. For ACI318 [11], $k$ $=1$ when walls are unrestrained against rotation at both ends.

More than 380 experimental test results on RC walls, conducted within the period 19742016, were collected in the literature and compiled in a database $[1,2,6,7,9,10,15-35]$. A number of research studies have focused on the behaviours of RC solid and opening walls, either in OW or TW4S. In particular, approximately $54.3 \%$ and $19.6 \%$ from the tests included in the database referred to OW and TW4S solid walls, respectively, and approximately $12 \%$ and $10.6 \%$ referred to OW and TW4S walls with openings, respectively. Little research has yet been conducted on TW3S walls. Altogether only three studies have been available to date: approximately $0.5 \%$ and $3.1 \%$ from the tests included in the database referred to TW3S solid 
and opening walls, respectively. While many researchers have investigated the behaviours of OW and TW4S solid and opening walls with several significant parameters such as slenderness ratio $\left(H_{w} / t_{w}\right)$ and aspect ratio $\left(H_{w} / L_{w}\right)$, all of the tested TW3S wall panels had the same slenderness ratio of 30 and aspect ratio of 1.00. Figure 2 encapsulates the geometric characteristics of $\mathrm{RC}$ walls documented in the database.

Table A1 (given in Appendix A) gives the concrete strengths $\left(f^{\prime}\right)$, wall dimensions, ultimate loads $\left(N_{u}\right)$, and axial strength ratios $\left(N_{u} / \mathrm{f}_{c}{ }_{c} L_{w} t_{w}\right)$ of walls in previous research publications $[2,6$, $7,29]$. The results of these experimental tests are reviewed in this section to identify issues in previous studies. Table A1 indicates the contradictory results among the collected data. The axial strength ratios were found to increase from OW to TW3S. As seen in Table A1, the axial strength ratios of OW50W1C1.2 to TSNC, O90W1C1.2 to TSHC and OW-NF to TW3S-NF led to percentage increases in strength of $21.0 \%, 79.0 \%$ and $49.7 \%$, respectively. However, Table A1 also reveals a contradiction of the aforementioned observation. In terms of walls having door type openings, the O65D1C1.2 and O65D1L1.2 panels with lower concrete strength and larger opening size had the same, and even higher, axial strength ratios compared with the TSHB600 panel. Similarly, a considerable discrepancy between research conducted by Doh et al. [7] and Lima et al. [2] was observed as well. In particular, the TSHC450, OW-NF and TW3S-NF specimens had identical opening dimensions. The concrete strength used for TSHC450 was higher than those used for OW-NF and TW3S-NF, yet relatively low ultimate strength was recorded for the TSHC450 wall. Additionally, Table A1 shows that an axial strength ratio of 0.196 was obtained for the TSNC specimen, whereas for the TSHC375, with much higher concrete strength ratio and slightly bigger opening size, a lower axial strength ratio (0.125) was achieved. Even though the effect of openings in the reduction of ultimate load capacity in RC walls is undeniable, the range of this effect still requires more research. Regarding the effect of opening positions, it was found that firstly the ultimate strength of walls $\left(H_{w} / t_{w}=30\right.$ and $\left.H_{w} / L_{w}=1.00\right)$ with an opening near the side restraint tended to be higher than for walls with an opening at the centre or near the free end, and secondly the walls with an 
opening at the centre had the lowest ultimate strength among the three opening locations [36]. These findings, however, differed from those of Doh et al. [6].

Many researchers, notably Fragomeni and Mendis [37], Doh and Fragomeni [27] and Lee [29] found that for a particular percentage increase in concrete strength, the test results of OW and TW4S walls did not provide the same percentage increase in wall strength. Moreover, the test results showed a lower percentage increase in wall strength. Doh and Fragomeni [27] proposed a formula varying with concrete strength function $\left(f_{c}^{\prime}\right)^{0.7}$ instead of $\left(f^{\prime}{ }_{c}\right)$. However, Table 2 indicates that the ultimate strength of the TW3S walls increased significantly when higher concrete strength was used, specifically with $60 \%$ increase in concrete strength (from 50.1 to $80.4 \mathrm{MPa}$ ) resulting in $61 \%$ enhancements in wall strength for a solid wall, $102 \%$ for a wall with an opening at the centre, and $159 \%$ for a wall with an opening near the side restraint.

Another issue is inaccuracies in the prediction of the code equations. The code equations were found to yield negative strength values for walls with various support conditions, indicating zero load-bearing capacity, in cases where $H_{w} / t_{w}>30$ with various $H_{w} / L_{w}$. These predictions are identified as inaccurate according to the test results of the previous experimental study [27]. Figure 3 depicts the effect on axial strength ratios versus aspect ratios for walls with various support conditions of $H_{w} / t_{w}=40$ and $e=t_{w} / 6$, particularly in predictions from the code equations compared to the test results. As seen in Figure 3, the code equations predicted zero strength for OW walls with all values of $H_{w} / L_{w}$. In addition, EC2 [12] and AS3600 [13] also predicted zero strength for TW3S and TW4S once the aspect ratios were varied, particularly when $H_{w} / L_{w} \leq 1.79$ and $H_{w} / L_{w} \leq 1.55$ with respect to TW3S for EC2 [12] and AS3600 [13] respectively, and $H_{w} / L_{w} \leq 0.59$ and $H_{w} / L_{w} \leq 0.52$ with respect to TW4S for EC2 [12] and AS3600 [13] respectively. However, the previous test results have evidently shown that OW and TW4S walls with $H_{w} / t_{w}$ up to 40 were capable of carrying significant loading. The same outcome is intuitively expected from TW3S walls with $H_{w} / t_{w}$ up to 40.

In summary, there is little research published on the behaviours of TW3S walls. Furthermore, a number of contradictions were observed in the experimental results in that 
research. The major design codes were found to be inadequate in predicting the failure load for TW3S walls of high slenderness ratios with various aspect ratios and/or with the presence of openings. The research on the behaviours of TW3S walls is thus, relatively unexplored.

\section{EXPERIMENTAL PROGRAM}

\subsection{Test specimens and material properties}

In the experimental program, twelve half-scale RC wall panels, including four solid panels and eight panels with an opening, were constructed and tested to failure. Scaling specimen sizes could lead to possible effects on the test results, however for the case of axially loaded concrete walls Seddon [38] found that scale effects were negligible. The half-scale was also employed in previous research $[6,7,27-29,35]$. The slenderness ratios of these walls varied from 25 to 40 along with varying aspect ratios from 0.83 to 1.60 . The ratio of opening size to total area of wall ( $A_{o} / A_{w}$, where $A_{o}=H_{o} \times L_{o}$ and $\left.A_{w}=H_{w} \times L_{w}\right)$ was chosen to be $5 \%$ or $10 \%$ where the height of the opening was equal to $1 / 3$ of the height of the wall. The objective was to investigate the effects of geometrical characteristics of the openings on the axial strength of TW3S walls. Typical details of the test panels are given in Figure 4. The geometric and material properties of the test panels are given in Table 3.

All the panels were reinforced with a single F41 mesh (4 mm diameter and $100 \mathrm{~mm}$ spacing) placed centrally within the panel cross-section. The vertical and horizontal reinforcement ratios $\rho_{v}$ and $\rho_{h}$ were both 0.0031 for all the panels, satisfying the minimum requirements in the code of standards to control cracking due to dry shrinkage. It should be noted that having a single mesh does not comply with the rules provided in AS3600-09 [13], which stipulates that two grids, one near each face of the wall, are required for walls designed for two-way buckling. Nonetheless, the formula for strength calculation in AS3600-09 [13] does not include any

reinforcement quantity, which can be interpreted that AS3600-09 [13] requires steel 
reinforcement in two layers for other than strength purposes. The additional reinforcement contribution to wall strength is also not reflected in other major code design equations $[11,12]$. In addition, the placement of minimum reinforcement at the mid-depth of the walls has little effect on axial load capacity, allowing the walls to be treated as unreinforced elements, as proved both theoretically and experimentally by previous research for both OW and TW4S walls $[14,39]$. The same outcome is intuitively expected from TW3S walls. Since the primary objective of this research was to evaluate the load capacity predictions of major design code equations, a single layer of reinforcement centrally placed was thus adopted in the experiment. In practical contexts, safe and conservative designs would be achieved when the wall is constructed with two layers of reinforcement. Additional short bars were placed diagonally at each corner of the openings to protect against cracks forming during stages of placing and curing. The design yield strength and the minimum tensile strength of the F41 mesh are 450 $\mathrm{MPa}$ and $500 \mathrm{MPa}$, respectively. Samples taken from the reinforcing steel meshes were tested to determine their actual properties. The average yield and tensile strengths were measured as 610 $\mathrm{MPa}$ and $645 \mathrm{MPa}$, respectively.

The concrete was obtained from a local ready mix supplier. General purpose cement, sand and $10 \mathrm{~mm}$ aggregates were used to produce concrete with a slump of $80 \mathrm{~mm}$. Wall panels were cast horizontally in purpose-made timber moulds with reinforcement secured at the centre of the cross-section using tie wires on $20 \mathrm{~mm}$ high plastic chairs. High-density polystyrene foam was placed in specific positions on the timber moulds to ensure openings were formed in the places required. The compressive strengths of wall panels (Table 3) were determined by standard sized concrete cylinders cured under the same moist-curing condition beside the wall panels.

\subsection{Test set-up and procedure}

The arrangement of the test set-up is shown in Figures 5(a-b). The test rig is capable of supporting axial loads of up to $2400 \mathrm{kN}$ using three independent hydraulic jacks, each of 800 $\mathrm{kN}$ capacity. The top and bottom hinged support conditions were each simulated by welding a 
high strength steel rod to a steel plate with an eccentricity of $t_{w} / 6$ from the centre line to simulate effects of imperfections in construction. At each contact surface between the specimen and the steel plate, a thin strap of deformable aluminium was inserted to avoid local damage due to surface irregularities. Details of the simply supported top hinged edge are shown in Figures 5(c-d). To simulate the hinged side support condition for two-way action, the edge of the wall panels had to be effectively stiffened in the perpendicular direction with allowed rotation along the wall panels. This was achieved by using a square hollow section to secure a pair of channels extending along the height of both sides of the test panel (Figures 5(e-f)).

Dial gauges were used to measure the out-of-plane deflections of the wall panels during testing. They were attached to the back of the wall or compression face. The lateral displacements of the test panels were measured in four places. Three dial gauges were positioned at the same locations for all the test specimens, including the dial gauge D1 at a distance from the free end of the wall of $175 \mathrm{~mm}$, the dial gauge D2 at a distance from the restrained end of the wall of $175 \mathrm{~mm}$, and the dial gauge D3 at a distance from the bottom of the wall of $200 \mathrm{~mm}$ (Figure 6). However, the location of the final dial gauge was varied for different panels and was placed at a distance from the top of the wall of $200 \mathrm{~mm}$ for several panels (WC1, WS2, WC2a, WC2b, WL2 and WR2), referred to as dial gauge D4 as indicated in Figure 6(a), or placed in the very centre of the panels (WS1, WL1, WR1, WD2, WS3 and WS4), referred to as dial gauge D5 as indicated in Figure 6(b).

A static loading regime was adopted for the testing. A load cell was positioned between the centre hydraulic jack and the upper loading beam. The walls were loaded in increments up to failure. At each load increment, crack patterns and deflections were recorded.

\section{NUMERICAL MODELLING USING ABAQUS}

\subsection{Material properties and constitutive models}




\subsubsection{Concrete}

Concrete damaged plasticity (CDP) was used to simulate the behaviours of concrete. The key factors of the model are yield criterion, flow rule, viscous parameter and damage variable. A summary of the CDP model parameters used for the numerical analyses is presented in Table 4, where $\psi$ is the dilation angle, $K_{c}$ is the ratio of tensile/compressive meridian, $\xi$ is the eccentricity, $\sigma_{b 0} / \sigma_{c 0}$ is the ratio of biaxial compressive strength/uniaxial compressive strength and $\mu$ is the viscosity parameter. Background details of these parameters can be found in the ABAQUS user's manual [43] and in the literature [44-47]. The tensile fracture and compressive plastic behaviour are completed by specifying the evolution laws of damage, which represents the stiffness degradation. The compression damage, $d_{c}$, and the tension damage, $d_{t}$, were calculated by the equations below after the peak stress [40]:

$$
\begin{aligned}
& d_{c}=1-\frac{\sigma_{c}}{f_{c}^{\prime}} \\
& d_{t}=1-\frac{\sigma_{t}}{f_{c t}^{\prime}}
\end{aligned}
$$

The complete stress-strain curve for unconfined concrete under compression was derived using the model proposed by Lu and Zhao [41]:

$$
\begin{array}{ll}
\sigma_{c}=f_{c}^{\prime}\left[\frac{\left(E_{c} / E_{0}\right)\left(\varepsilon / \varepsilon_{0}\right)-\left(\varepsilon / \varepsilon_{0}\right)^{2}}{1+\left(E_{c} / E_{0}-2\right)\left(\varepsilon / \varepsilon_{0}\right)}\right] & \text { for } 0 \leq \varepsilon \leq \varepsilon_{L} \\
\sigma_{c}=f_{c}^{\prime}\left[1+0.25\left(\frac{\varepsilon / \varepsilon_{0}-1}{\varepsilon_{L} / \varepsilon_{0}-1}\right)^{1.5}\right]^{-1} & \text { for } \varepsilon>\varepsilon_{L}
\end{array}
$$

in which $\varepsilon_{0}=700 f^{\prime}{ }_{c}^{0.31} \times 10^{-6}, E_{0}=f^{\prime}{ }_{c} / \varepsilon_{0}$ and $\varepsilon_{L}=\varepsilon_{0}\left[\left(0.1 \frac{E_{c}}{E_{0}}+0.8\right)+\sqrt{\left(0.1 \frac{E_{c}}{E_{0}}+0.8\right)^{2}-0.8}\right]$. The modulus of elasticity $\mathrm{E}_{\mathrm{c}}$ is calculated from the equations in AS3600-09 [13].The value of $\varepsilon_{L}$ corresponds to stress level of $0.8 f_{c}^{\prime}$ on the descending branch of the stress-strain curve.

The tensile stiffening model proposed by Fields and Bischoff [42] was used for simulation: 


$$
\begin{array}{ll}
\sigma_{t}=E_{c} \varepsilon & \text { for } 0 \leq \varepsilon \leq \varepsilon_{c r} \\
\sigma_{t}=e^{-0.8\left(\varepsilon-\varepsilon_{c r}\right) \times 10^{3}} E_{c} \varepsilon_{c r} & \text { for } \varepsilon_{c r}<\varepsilon
\end{array}
$$

where $\varepsilon_{c r}=f^{\prime}{ }_{c t} / E_{c}$ and $f_{c t}^{\prime}=0.36 \sqrt{f_{c}^{\prime}}$ as specified in the AS3600-09 [13].

\subsubsection{Steel reinforcement and steel restraints}

The stress-strain curve for the steel reinforcement was assumed to be the elastic-perfectly plastic material and identical in compression and tension. The steel restraints were assumed to behave in a linearly elastic manner. As it is commonly used for most steel types, the elastic modulus for steel was taken to be $E_{s}=210 \mathrm{GPa}$.

\subsection{Numerical analysis and nonlinear solution}

The concrete was modelled by the use of C3D8R elements, eight-node brick with reduced integration and hourglass control. The steel reinforcement was represented by discrete truss elements in linear (T3D2) order. The reinforcement was embedded in the concrete region with a perfect bond. The rough friction formulation was implemented in order to prevent the wall from losing contact with the restraints, so that boundary conditions could be correctly applied. Both $\mathrm{RC}$ wall and restraints were assumed to be impenetrable rigid bodies by hard contact simulation. The modified Riks method was used for analysis of all numerical models. Automatic stability was used to avoid divergence solutions. For considering the geometric nonlinearity, the Nlgeom setting was also activated. Mesh convergence studies were conducted, arriving at appropriate meshes which provided a relatively accurate solution with low computational time.

\section{RESULTS AND DISCUSSION}

\subsection{FE-Model validation}


In order to establish the FEM as an effective tool for predicting the failure characteristics of TW3S walls in the current study, a benchmark study was carried out using the test results from previous research $[2,10,27,29,35]$.

In Table 5, the results show that the ratios of the FEM to the test failure varied from 0.71 to 1.18, with a mean of 0.97 and a standard deviation of 0.11 (The details of the experiments can be found in Table A1 - Appendix A). This shows a good agreement between the FEM and the test results as the FEM is an idealistic model in which there is no variation in material and section properties.

The crack patterns in the concrete structure using CDP model can be visualised by the concept of an effective crack direction [43]. The direction of the vector normal to the crack plane is assumed to be parallel to the direction of the maximum principal plastic strain (PE, Max. Principal). Figure 7 illustrates that the cracking behaviour was well predicted by the FEM, indicating the simulations were able to capture the failure mechanism in the test specimens. A larger number of cracks spread over a greater area can be seen in the FEM results as compared to the experimental observations. This is because a crack is displayed at any point at which the tensile equivalent plastic strain is greater than zero and the maximum principal plastic strain is positive regardless of the length or width of the crack. In the experiments, however, many of the smaller cracks were either not visible to the human eye or merged together forming a larger and more localised crack.

In summary, the FEM ultimate loads and crack patterns show close correlation to the experimental observations. The modelling techniques adopted to simulate the wall panels are thus proven to be satisfactory, which can be used for validation of current test results.

\subsection{Cracking characteristics}

Figure 8 shows the crack patterns after collapse for the panels tested. All tested panels experienced biaxial bending behaviour near side restrained and exhibited crack patterns that are consistent with the expected behaviour of wall panels supported on three sides as idealised in 
Figures 1(b-c). Typically, sudden and explosive types of failures, mostly due to buckling (intensified by bending) with the crushing of concrete on the compression faces and some yielding of reinforcement taking place, were observed for most panels. The majority of cracking propagated diagonally from the restrained corners, and then split into two separate parts in the region of the unrestrained edge. The particular cracking mode indicates two-way behaviour close to the restrained end and one-way behaviour close to the free end.

No crack was observed until failure for the solid walls. The energy was dissipated through the two diagonal cracks that developed at roughly $45-55^{\circ}$ inclination from the top and bottom corners for the WS1, WS2 and WS4 panels, and $50^{\circ}$ and $35^{\circ}$ inclination from the top and bottom corners respectively for the WS3 panel. Also, several smeared diagonal (secondary tensile) cracks were distributed around the major cracks.

In respect to opening walls, the cracking loads were about $23 \%$ to $84 \%$ of ultimate loads. Several vertical cracks developed on the top and bottom edges of openings during the loading stage. This is because the presence of the openings affects the ability of the wall to redistribute stresses and also creates stress concentrations around the opening, encouraging cracks to occur first around the corners of the opening. The diagonal cracks developed at roughly $40-55^{\circ}$ inclination from the top and bottom corners of the walls. The failure modes of opening walls were mostly identical to those of solid walls.

The FEM results are also presented in Figure 8 for comparison. However, not all the FEM results are shown here for brevity. Overall, the FEM results revealed similar crack patterns (see Figures 8(a-f)) which clearly validated the experimental results.

The effective height factors $(k)$ provided in EC2 [12] and AS3600 [13] were adopted from the German Code [48]. Nonetheless, nothing in the literature has been found regarding how these effective height factor formulae have been derived. Fragomeni [24] attempted to derive the formulae by using the Timoshenko plate theory. The effective height factor for a plate supported on three sides can be expressed as: 


$$
k=\frac{1}{\sqrt{0.456\left(H_{w} / L_{w}\right)^{2}+1}}
$$

Table 6 presents the locations of the horizontal cracks $\left(H_{c}\right)$ for the tested TW3S panels where the maximum deflection in each panel occurred. These horizontal cracks were the lesser of the average distance measured from either top or bottom of the test panels. The effective heights of the walls $\left(H_{w e}=k H_{w}\right)$ computed from the design codes and Equation (7) are also included in Table 6. Note that AS3600 [13] only allows the effects of openings in TW4S walls to be neglected if the total area of openings does not exceed $1 / 10$ of the area of the wall, and the height of any opening does not exceed 1/3 of the height of the wall. However, EC2 [12] allows for walls with various edge conditions. Thus, the effective height formula was also employed to calculate for the walls with openings as the dimensions of the openings in this study do not exceed the size threshold. Recognisably, the values of $2 H_{c}$, corresponding to the occurrence of half wave, were relatively close to $H_{w e}$ computed from the design codes. In addition, the effective height factors given in design codes are larger than those calculated from Equation (7). This was postulated by Fragomeni [24] as the conservative approach taken by design codes in formulating the effective height factor. Due to the uncertainty of concrete cracks occurring during loading, the stiffness of the section might be significantly reduced and the supported edge might lose its restraint capabilities [24]. These reasonably suggest the applicability of using the formulae as stipulated in design codes to calculate the effective height for TW3S walls with and without openings.

\subsection{Axial load versus lateral deflection curves}

Typical relations of load to lateral deflection for wall panels are shown in Figure 9. The maximum deflections were obtained just prior to the failure load being reached. The tested panels failed in a brittle mode and the sudden failure of these panels made it difficult to record deflections precisely at failure. Thus in these figures, the absolute maximum failure loads and the corresponding maximum deflections are not shown. The specimens showed a brittle type of 
failure in which they were unable to sustain any further loading after reaching the maximum load. Figures 9(a-b), (d), and (f) show that the deflections at the free end, measured by D1, are generally in proportion to the deflections at the wall centre and at the restrained end, measured by D5 and D2 respectively. Also, the readings for the top and bottom dial gauges, measured by D4 and D3 respectively, shown in Figures 9(c) and (e), are similar. This indicates the data gives a reasonably accurate indication of load versus lateral deflection measurement. The wall panels initially deflected due to the eccentricity of load and then amplified deflection due to $P$ - $\triangle$ effects. The load-deflection paths are typified by linear portions, with the linearity of the curves up to 45 to $67 \%$ of the ultimate loads, followed by an increasing non-linear curve as the lateral deflection increases rapidly to failure. The difference of deflection profiles of the solid panel and opening counterparts can be noted by the fact that larger lateral deflections at failure were obtained for the solid panel.

The load-deflection responses of typical panels predicted by FEM were also presented in Figure 9. The slopes of the load-deflection curves were obviously steeper in the case of FEM results than those of experimental results. The FEM results also showed a more linear loaddeflection path early before becoming nonlinear, whereas test results showed a more nonlinear load-deflection path early in their history. This is expected as the FEM is an idealistic model which idealises possible dimensional variations, material irregularities, concrete voids, changes in reinforcement location, and the variations in restraint or loading conditions. Such ideal conditions are rarely found in practice or even in the more controlled laboratory work. These all can be seen as contributing to the reduced failure loads of the wall panels in the experimental tests.

\subsection{Ultimate strength}

Due to the inapplicability of the ACI318 [11] method for predicting load capacity of walls with the presence of side restraints, Equation (1) was excluded from the comparison of test results. 
Table 7 presents the ultimate loads, $N_{u}$, the non-dimensional parameter of axial strength ratios, $N_{u} / f^{\prime}{ }_{c} L_{e f f} t_{w}$ and the ultimate loads predicted by FEM as well as Equations (2) and (3) for all test panels. In general, Equations (2) and (3) are inadequate in predicting failure load for TW3S walls under many circumstances. The FEM ultimate load predictions are satisfactory but slightly overestimated. The ratios of the FEM to experimental failure loads varied from 0.89 to 1.23 , with a mean value of 1.09 and a standard deviation of 0.11 .

\subsubsection{Results of solid panels}

It can be seen that the code formulae are generally conservative for concrete walls over a range of slenderness values. For example, when $H_{w} / t_{w}=40$, the code formulae would give approximately zero or negative values (zero load carrying capacities), which is clearly not the case as actual test results produced significant load capacities for these panels. Further, the ultimate strength of the WS3 panel $\left(H_{w} / t_{w}=35\right)$ was also much higher than that predicted by code formulae, even though the panel was damaged prior to testing.

To investigate the behaviour of solid walls with various support conditions, the current test result of panel WS2 is plotted against the previous test failure load data (Figure 10(a)) of Wong [26], Doh and Fragomeni [27] and Doh et al. [6]. The data is comparable as all tests were undertaken on walls at a load eccentricity of $e=t_{w} / 6$, concrete strengths up to $100 \mathrm{MPa}$ and vertical reinforcement ratios between 0.0031 and 0.01 , where a single layer of reinforcement was placed centrally (Table A1, Appendix A). Ho et al. [14] and Fragomeni and Mendis Error! Reference source not found. found that reinforcement ratios in this range showed a negligible influence on ultimate load capacity. According to test results, the axial strength ratios for the TW3S were lower than for the TW4S, but higher than for the OW panels. Further, for TW3S walls, the axial strength ratio tended to increase with an increase in aspect ratio, while for OW walls the opposite trend was found. More specifically, for TW3S panels it is observed that there was a slight increase in axial strength ratio (approximately 1.67\%) when $H_{w} / L_{w}$ was increased from 1.00 to 1.20 . For OW walls, an average reduction in the axial strength ratio was $19.9 \%$, 
for an increase of $H_{w} / L_{w}$ from 0.75 to 1.00 . A similar observation was also reported by Saheb and Desayi [19]. Notably, a linear reduction trend of ultimate strength was noticed with an increase in $H_{w} / L_{w}$ from 0.67 to 2.00 [19]. In general, these results indicate that when the aspect ratio increases, the axial strength ratios of OW and TW3S tend to diverge, highlighting the perceived advantage of TW3S over corresponding OW walls due to great increases in wall strength from OW to TW3S being likely to be gained.

To verify aforementioned observations, FE analysis was then undertaken. All the simulated panels were subjected to loads with the eccentricity of $t_{w} / 6$ and with the centrally placed reinforcement ratio being equal to 0.0031 . Walls with various support conditions of $H_{w} / t_{w}=30$ along with a concrete strength of $50 \mathrm{MPa}$ were studied with variation in $H_{w} / L_{w}$ from 0.3 to 3.00 . Results of this analysis are presented in Figure 10(b) showing that when the values of $H_{w} / L_{w}$ became increasingly greater, the axial strength ratios of TW3S and OW panels diverged. For example, the axial strength ratios of the TW3S wall over the corresponding OW wall with $H_{w} / L_{w}=0.30$ led to the percentage increase in strength of $6.5 \%$; however, the percentage increase in wall strength for walls with $H_{w} / L_{w}=3.00$ was up to $117.5 \%$. This further implies that despite being safe to design the TW3S walls as OW walls, this could be too conservative and uneconomical owing to requiring a considerable amount of construction material and cost for building construction in many cases. Hence, enormous savings may be achieved if an accurate, less conservative design of RC walls can be carried out.

\subsubsection{Results of panels with openings}

The EC2 equation can be used for predicting the ultimate capacity of currently tested TW3S walls with openings, as the investigated opening dimensions do not exceed the size threshold [12]. As indicated in Table 7, all the panels had predicted failure loads below their tested failure loads. The average of predicted load to experimental load is 0.51 with a standard deviation of 0.14. If $\phi=0.67$ was used in the design, then Equation (2) would give safe but very conservative design values for those panels. 
Further inspection of Table 7 reveals that, based on the experimental results, the 5\% and $10 \%$ reductions in the area of the solid wall $\left(H_{w} / t_{w}=30, H_{w} / L_{w}=1.2\right)$ caused by introducing the openings at the centre reduced its load carrying capacity by $10.2 \%$ and $17.0 \%$, respectively. The FEM results reveal $18.7 \%$ and $32.0 \%$ reductions in wall strength, respectively. These variables show a slightly nonlinear correlation (Figure 11). Additionally, the $10 \%$ reductions in the area of the solid wall $\left(H_{w} / t_{w}=25, H_{w} / L_{w}=0.83\right)$ caused by introducing the openings, while varying the opening location left, centre or right, about the central horizontal axis of the walls, led to $14.6 \%, 17.3 \%$ and $22.5 \%$ reductions in wall strengths, respectively. The FEM results demonstrate $24.8 \%, 30.9 \%$ and $28.1 \%$ reductions in wall strength, respectively. Note that the test results of WS1, WL1, WC1 and WR1 as well as WS2, WL2, WC2b and WR2 are considered to be comparable due to the difference between the concrete strengths of solid and opening walls being only $0.68 \%$.

The experimental and FEM results (see Figure 12) also highlight that the positions of the openings greatly affect the behaviour of a TW3S wall as they appear to have offset the perceived advantages gained from having a side restraint. A difference between experimental and FEM results is noticed in Figure 12(a). In the experiment, the WR1 panel possessed the lowest ultimate strength among the three opening locations, while in the analysis the WR1 panel had a higher strength compared to the WC1 panel. This discrepancy may be due to experimental error. Regarding experimental results, Figure 12(b) shows that as the distance between the vertical restraint and the opening location increased, the ultimate strength of the wall panel increased. A similar trend was also observed in the FEM results. Further, the wall strength of the WL2 panel was observed to be smaller than that of the panels with an opening far away from the restraint, while the WL1 panel possessed the highest ultimate strength among the three opening locations. This complex behaviour could be attributed to the effects of the wall shape $\left(H_{w} / L_{w}\right)$ and/or opening shape $\left(H_{o} / L_{o}\right)$. However, it is inappropriate to suggest a conclusive result for the actual influences of these factors until further studies are conducted. 
Interestingly, the axial strength ratio responses differed remarkably (Figures 11 and 12). In some cases, the axial strength ratios of walls with openings were higher than those of the solid walls. Also, the axial strength ratio of the wall in which $A_{o} / A_{w}=10 \%$ was higher than that of the wall in which $A_{o} / A_{w}=5 \%$ (WC2b versus WC2a). This may be due to the boundaries becoming more active in the portions that exhibited column element action, thereby utilising the material's strength more effectively in compression [35].

\section{THE PROPOSED ULTIMATE LOAD PREDICTION USING RIGID-PLASTIC}

\section{APPROACH}

The rigid-plastic approach, also known as the yield line theory, can be carried out by the virtual work method. The method assumes that at collapse the work done due to a virtual imposed displacement is equal to the internal work dissipated along the yield lines. For TW4S walls with the transverse loads accompanied by in-plane loads (Figure 13), Popescu et al. [8] developed a general work equation of the following form:

$$
\sum\left(\iint S_{u} \delta d x d y\right)_{\text {each region }}-\int\left(n_{u x, u y} \delta d x, y\right)_{\text {each boundary }}=\sum\left(\int m_{b} \theta d s\right)_{\text {each yield line }}
$$

where $S_{u}$ is the uniformly distributed transverse load per unit area, $\delta$ is the virtual displacement, $n_{u x}, n_{u y}$ are the uniform in-plane compressive force per unit length applied in the $x$ (horizontal) and $y$ (vertical) directions respectively, $m_{b}$ is the bending moment, and $\theta$ is the rotation of the region about its axis of rotation.

For axially loaded walls, the compressive forces govern the failure which means that $n_{u y} \gg>$ $S_{u}$. The contribution of the reinforcement is neglected for lightly-reinforced walls due to the main purpose of reinforcement being to control cracking from creep, shrinkage and erection/transportation loads. The internal work is determined by replacing the bending moment $m_{b}$ with the membrane moment $m_{c}$ in the yield line solution, which can be expressed as: 


$$
m_{c}=\frac{1}{4} v_{1} f_{c}^{\prime}\left(t_{w}-\delta_{p}\right)
$$

where $\delta_{p}$ is the maximum deflection exhibited by the experimentally studied walls before undergoing plastic collapse, $v_{l}$ is the effectiveness factor expressed as the product of $\eta_{f c}$ and $\eta_{\varepsilon}-$ strength reduction factors reflecting the brittleness of concrete and the influence of transverse cracking, respectively.

$$
v_{1}=\eta_{f c} \eta_{\varepsilon}, \eta_{f c}=\left(\frac{f_{c 0}}{f_{c}^{\prime}}\right)^{1 / 3} \leq 1, f_{c 0}=30 \mathrm{MPa}, \eta_{\varepsilon}=0.55
$$

The predictions showed reasonably good agreement with experimental test data [8]. However, the scope of the analysis approach is limited due to the exact yield line patterns and the values of maximum displacement parameter being usually unavailable to put into practice. In terms of the yield lines, various patterns can be assumed, depending on the opening size and position as well as slenderness and aspect ratios. Consequently, it could require engineering practitioners to devote considerable efforts to obtain such solutions. Regarding the maximum out-of-plane displacement at peak load, Popescu et al. [8] recommended the use of the Australian code for the estimations. To verify the applicability of Australian equations for calculations of the ultimate displacements, a comparison between the theoretical values and experimentally obtained results needs to be conducted. Nevertheless, the tested panels in this study failed in a brittle mode and the sudden failure of these panels, with the use of dial gauges for deflection record, made it difficult to obtain deflections at failure (as above-mentioned in Section 5.3). The comparison between the theoretical and experimental maximum displacements cannot be made. Furthermore, the maximum displacements were not usually available in the previous research as well. Only a few studies $[1,8,10]$, including OW and TW4S walls, were found and a significant discrepancy between the theoretical and experimental values could be easily observed once the comparison is made. For the sake of brevity, the comparison will not be presented here. The difference might be attributed to the following reasons. In the theoretical formula, the deflections only account for the element's initial stiffness 
and do not include nonlinear deflections [8]. Concerning the experimental results, the deflections could be significantly affected by test uncertainties in material or geometric and load variables.

Since the available models for estimating the ultimate strength of TW3S walls with and without openings are rare and inapplicable for many cases, a simplified empirical model, which incorporates the rigid-plastic approach developed by Popescu et al. [8], was therefore proposed in this study to overcome the current shortcomings. Based on aforementioned observations and discussions, some assumptions involved in the rigid-plastic approach for TW3S walls are as follows:

1. Due to the challenge of the determination of exact solutions for the yield lines, simplified layouts of yield lines for TW3S walls with and without openings are proposed (see Figure 14), which has been justified by the experimental observations reported in Section 5.2. It is assumed that the layouts of yield lines include the real and the fictitious yield lines. The normal rotations of the yield lines $\theta$ would be the same for both solid and opening walls of the same dimensions $\left(H_{w} \times L_{w} \times t_{w}\right)$. The internal work dissipated along the real yield lines is equal to the work done by the applied loads. The diagonal yield line from the bottom of a wall develops with $\varphi$ inclination, where $\varphi=40^{\circ}$ when $H_{w}<L_{w}$ and $\varphi=50^{\circ}$ when $H_{w} \geq L_{w}$. The selected angle values, which are within the observed range in the experiment, were arrived at by trial and error fitting with FEM results. The location of the horizontal yield line is assumed to be equal to half of the effective height, $H_{w e}$, from the bottom of the walls, where $H_{w e}=k H_{w}$ is defined in [13].

2. The maximum displacement at peak load $\delta_{p}$ is calculated as $\delta_{p}=\lambda e_{a}$, where $e_{a}$ is the lateral deflection for TW3S walls defined in [13], $\lambda=A /\left(\eta_{o x} / \eta_{o y}\right)^{B}+C$ is a fine-tuning parameter in which $A, B$ and $C$ factors were calibrated from the FEM results using regression analysis. In particular, $A, B$ and $C$ are equal to $0.12,0.22$ and 1.19 , respectively. Note that the equation was calibrated to only satisfy the equilibrium in the work equation and probably not reflect the actual out-of-plane displacements in reality. 
The external and internal work can be obtained using Equation (8) and used to derive a failure load. By way of illustration, the following equations were derived.

For solid walls (Figure 14(a)), $\frac{t_{w}}{3} n_{u y} L_{w}\left(\theta_{1}+\theta_{2}\right)=m_{c}\left[L_{w}\left(\theta_{1}+\theta_{2}\right)+H_{w} \theta_{3}\right]$, which leads to the expression:

$$
N_{u}=3 m_{c}\left[\left(\frac{L_{w}}{t_{w}}\right)+\tan (\varphi)\left(\frac{2-k}{2}\right)\left(\frac{H_{w}}{t_{w}}\right)\right]
$$

For walls with an opening located outside the region of diagonal yield lines (Figure 14(b)), $\frac{t_{w}}{3} n_{u y}\left(L_{w}-L_{o}\right)\left(\theta_{1}+\theta_{2}\right)=m_{c}\left[\left(L_{w}-L_{o}\right)\left(\theta_{1}+\theta_{2}\right)+H_{w} \theta_{3}\right]$, which leads to the expression:

$$
N_{u}=3 m_{c}\left[\left(\frac{L_{w}-L_{o}}{t_{w}}\right)+\tan (\varphi)\left(\frac{2-k}{2}\right)\left(\frac{H_{w}}{t_{w}}\right)\right]
$$

For walls with an opening located within the region of diagonal yield lines - Pattern 1 (Figure $14(\mathrm{c})), \frac{t_{w}}{3} n_{u y}\left(L_{w}-L_{o}\right)\left(\theta_{1}+\theta_{2}\right)=m_{c}\left[\left(H_{w}-H_{o}\right)\left(\frac{\theta_{1}+\theta_{2} \tan \alpha}{2}+\theta_{3}\right)+\left(L_{w}-\frac{L_{o}}{2}-\eta_{o x}\right)\left(\theta_{1}+\theta_{2}\right)\right]$, which leads to the expression:

$$
N_{u}=3 m_{c}\left[\left(\frac{L_{w}-\left(0.5 L_{o}+\eta_{o x}\right)}{t_{w}}\right)+\left\{\frac{\left[2 \tan ^{2}(\varphi)+1\right](2-k)^{2}+k^{2}}{4(2-k) \tan (\varphi)}\right\}\left(\frac{H_{w}-H_{o}}{t_{w}}\right)\right]
$$

Some of the symbols used in the equations are identified in Figures 13 and 14, where $\theta_{1}=$ $2 \delta / H_{w e}, \theta_{2}=2 \delta /\left(2 H_{w}-H_{w e}\right), \theta_{3}=\delta / L_{x}=2 \tan (\varphi) \delta / H_{w e}, \tan \alpha=H_{w e} /\left[\left(2 H_{w}-H_{w e}\right) \tan (\varphi)\right], \mathrm{G}$ is the centre of gravity of the opening and other variables are as defined earlier.

Table 8 gives test panel predicted and test failure loads including the ratio of predicted results to test results of the present and previous studies. The average predicted to test ratio for all panels is 1.07 with a standard deviation of 0.14 , which clearly shows slight over-prediction. However, it should be noted that in design, safe prediction can be obtained when a strength reduction factor $\phi$ is carefully optimised. 


\section{CONCLUSIONS AND FUTURE DIRECTIONS}

An experimental study was undertaken on a total of twelve half-scale three-side restrained RC walls with and without openings subjected to eccentric axial loadings, to obtain a better understanding of the structural behaviour of the walls in terms of cracking characteristics, loaddeflection responses and ultimate strengths. Actual test failure loads were used to investigate the applicability of concrete wall design equations in current codes of practice. The code design formulae were found to be either inapplicable to walls with and without openings of high slenderness ratios with various aspect ratios, or inadequate in predicting failure load for such walls, where predictions yield very conservative or even zero capacity. These predictions are clearly not the case, as test results indicate that significant capacities can be achieved.

The current test results were also validated by the FEM simulations using ABAQUS software. The effectiveness of the numerical modelling technique for predicting the behaviour of concrete walls was initially demonstrated by a successful comparative study with other test results from the literature of walls with various support conditions. The FEM crack patterns, deflections and ultimate loads show close correlation to the current test observations. Some discrepancies between the experimental and numerical results could be attributed to experimental errors and uncertainties as well as the idealistic nature of the FEM. In general, the FEM model has been established as a satisfactory and effective tool for predicting the ultimate strengths of concrete walls, which could be employed as a cost-effective and more accurate option for future in-depth investigations.

Due to the fact that there are limited available methods for predicting the ultimate loads of TW3S walls, this study has proposed a simplified empirical model, which is a modification of the rigid-plastic approach. The model gave a reasonable prediction of axial load capacity when compared with experimental results. However, because this model was calibrated with limited FEM results and was based on several assumptions from experimental observations, more 
experimental and numerical research is required to cover a wider range of practical application.

These include slenderness and aspect ratios as well as opening size and location, all of which may have an influence on the layout of the yield lines. This would help to further validate and refine the proposed model, improving its applicability and establishing more accurate design aids for this important class of concrete structures.

\section{ACKNOWLEDGEMENT}

The first author would like to acknowledge Griffith University for the support of his full $\mathrm{PhD}$ scholarship. The authors also would like to acknowledge the technical support from Messrs Chuen Lo and Geoff Turner from Griffith School of Engineering, Griffith University Gold Coast Campus.

\section{APPENDIX A}

\section{REFERENCES}

[1] J.G. Sanjayan, T. Maheswaran, ACI Struct. J. 1999, 96, 571.

[2] M.M. Lima, J.-H. Doh, D. Miller, Experimental study of RC walls with openings strengthened by CFRP, Proceedings of $23^{\text {rd }}$ Australian Conference on the Mechanics of Structures and Materials, 2014.

[3] C. Popescu, G. Sas, T. Blanksvärd, B. Täljsten, Eng. Struct. 2015, 89, 172.

[4] A.E. Seddon, The strength of concrete walls under axial and eccentric loads, Symposium on the Strength of Concrete Structures, London, UK 1956.

[5] B.S. Mohammed, L.W. Ean, K.M.A Hossain, Int. J. Eng. Res. Appl. 2011, 1, 1841.

[6] J.-H. Doh, D.J. Lee, H. Guan, Y.C. Loo, Concrete wall with various support conditions. Proceedings of $4^{\text {th }}$ International Conference on Advances in Structural Engineering and Mechanics, Korea 2008.

[7] J.-H. Doh, Y.C. Loo, S. Fragomeni, Concrete walls with and without openings supported on three sides, Incorporating Sustainable Practice in Mechanics and Structures of Materials, 2010.

[8] C. Popescu, J.W. Schmidt, P. Goltermann, G. Sas, Eng. Struct. 2017, DOI: 10.1016/j.engstruct.2017.07.069.

[9] G.P. Robinson, A. Palmeri, S.A. Austin, Eng. Struct. 2013, 56, 1945.

[10] Y. Huang, E. Hamed, Z.T. Chang, S.J. Foster, J. Struct. Eng. 2015, 141.

[11] ACI Committee 318, Building code requirements for structural concrete (ACI318-14) and commentary, American Concrete Institute, Farmington Hills, MI, USA 2014.

[12] EN 1992-1-1, Eurocode 2: design of concrete structures - Part1 - 1: General rules and rules for buildings, Comité Européen De Normalisation, Brussels 2004. 
[13] AS3600-09, Concrete structures, Standards Association of Australia, North Sydney, NSW, Australia 2009.

[14] N.-M. Ho, J.-H. Doh, S. Fragomeni, Struct. Des. Tall Special Build. 2017, DOI: 10.1002/tal.1353.

[15] S.E. Swartz, V.H. Rosebraugh, S.A. Rogacki, Exp. Mech. 1974, 14, 139.

[16] G.D. Oberlender, N.J. Everard, ACI Struct. J. 1977, 74, 256.

[17] S.U. Pillai, C.V. Parthasarathy, Build. Environ. 1977, 12, 25.

[18] Z.A. Zielinski, M.S. Troitsky, H. Christodoulou, ACI Struct. J. 1982, 79, 313.

[19] S.M. Saheb, P. Desayi, J. Struct. Eng. 1989, 115, 2617.

[20] S.M. Saheb, P. Desayi, J. Struct. Eng. 1990, 116, 1384.

[21] S.M. Saheb, P. Desayi, J. Struct. Eng. 1990, 116, 1565.

[22] M. Waddick, B. Swifte, Buckling of thin-walled concrete structure, Structural Engineering Report, Monash University, Australia 1991.

[23] D. Roongsang, Buckling of reinforced concrete walls with simply supported side edges, Structural Engineering Report, Monash University, Australia 1994.

[24] S. Fragomeni, Design of normal and high strength reinforced concrete walls. Ph.D. Dissertation, University of Melbourne, Australia 1995.

[25] J.G. Sanjayan, Mag. Concr. Res. 2000, 52, 169.

[26] F.H. Wong, Behaviour of slender high strength concrete wall panels with opening, Master Thesis, Monash University, Australia 2000.

[27] J.-H. Doh, S. Fragomeni, Aust. J. Struct. Eng. 2005, 6, 37.

[28] J.-H. Doh, S Fragomeni, Adv. Struct. Eng. 2006, 9, 103.

[29] D.J. Lee, Experimental and theoretical study of normal and high strength concrete wall panels with openings. Ph.D. Dissertation, Griffith University, Australia 2008.

[30] N. Ganesan, P.V. Indira, S. Rajendra Prasad, Int. J. Earth. Sci. Eng. 2009, 2, 340.

[31] N. Ganesan, P.V. Indira, S. Rajendra Prasad, Struct. Eng. Mech. 2010, 36, 1.

[32] N. Ganesan, P.V. Indira, S. Rajendra Prasad, Strength and behavior of SFRSCC and SFRC wall panels under one-way action, High Performance Fiber Reinforced Cement Composites 6, Netherlands 2012.

[33] N. Ganesan, P.V. Indira, A. Santhakumar, Constr. Build. Mater. 2013, 48, 91.

[34] B. Mohammed, L.W. Ean, M.A. Malek, Constr. Build. Mater. 2013, 40, 575.

[35] C. Popescu, G. Sas, C. Sabău, T. Blanksvärd, J. Struct. Eng. 2016, DOI: 10.1061/(ASCE)ST.1943-541X.0001558.

[36] N.,-M. Ho, M.M. Lima, J.-H. Doh, Axially loaded three-side restrained reinforced concrete walls: a comparative study, Proceedings of $24^{\text {th }}$ Australian Conference on the Mechanics of Structures and Materials, Perth 2016.

[37] S. Fragomeni, P.A. Mendis, Struct. Concr. 2001, 2, 15.

[38] A.E. Seddon. , Concrete walls in compression under short-term axial and eccentric loads, International Association for Bridge and Structural Engineering (IABSE), Switzerland 1956.

[39] S. Fragomeni, P. Mendis, J. Struct. Eng. 1997, 123, 680.

[40] M.M. Lima, J.-H. Doh, M.N.S. Hadi, D. Miller, Struct. Des. Tall Special Build. 2016, DOI: 10.1002/tal.1282.

[41] Z.H. Lu, Y.G. Zhao, J. Mater. Civ. Eng. 2010, 22, 1487.

[42] K. Fields, P.H. Bischoff, ACI Struct. J. 2004, 101, 447.

[43] H. Hibbitt, B. Karlsson, P. Sorensen, ABAQUS analysis user's manual version 6.10, Dassault Systèmes Simulia Corp., USA 2011.

[44] M.P. Nielsen, Limit analysis and concrete plasticity, CRC Press, 1999.

[45] J.F. Jiang, Y.F. Wu, Int. J. Solids. Struct. 2012, 49, 445.

[46] S.S. Lee, J. Moon, K.S. Park, K.W. Bae, Sci. World. J. 2014, DOI: 10.1155/2014/474728.

[47] A.A. Valls, J.M. Carreras, Influence of outer diameter in confinement effect of CFT sections under bending, Proceedings of $15^{\text {th }}$ International Symposium on Tubular Structures, 2015.

[48] DIN 1045, Reinforced concrete structures: design and construction, Deutsches Institut Für Normung, Berlin 1988. 
Table 1. Design equations specified in standards.

\begin{tabular}{cl}
\hline Code & Expression \\
\hline ACI318-14 [11] & $N_{d}=\phi N_{u}=\phi 0.55 L_{w} f_{c}^{\prime}\left[1-\left(k H_{w} / 32 t_{w}\right)^{2}\right] t_{w}$ \\
& $N_{d}=L_{w} f_{c}^{\prime} \Phi t_{w} / \gamma_{c}$ \\
& in which \\
EC2-04 [12] & $\Phi=1.14 \times\left(1-2 \frac{e+e_{a}}{t_{w}}\right)-0.02 \times \frac{H_{w e}}{t_{w}} \leq\left(1-2 \frac{e+e_{a}}{t_{w}}\right)$ \\
AS3600-09 [13] & $N_{d}=\phi N_{u}=\phi 0.6 L_{w} f_{c}^{\prime}\left(t_{w}-1.2 e-2 e_{a}\right)$ \\
\hline
\end{tabular}

Table 2. Comparison of percentage increase in wall strength.

\begin{tabular}{|c|c|c|c|}
\hline \multirow{2}{*}{ Panel } & \multirow{2}{*}{$N_{u}(\mathrm{kN})$} & \multicolumn{2}{|c|}{ Percentage increase in strength $(\%)$} \\
\hline & & Test & Doh and Fragomeni [27] \\
\hline TSHO & 809.3 & \multirow{2}{*}{61.0} & \multirow{2}{*}{39.0} \\
\hline TSNO & 502.2 & & \\
\hline TSHC & 715.2 & \multirow{2}{*}{102.2} & \multirow{2}{*}{39.0} \\
\hline TSNC & 353.2 & & \\
\hline TSHL & 668.1 & \multirow{2}{*}{159.0} & \multirow{2}{*}{39.0} \\
\hline TSNL & 257.5 & & \\
\hline
\end{tabular}

Table 3. Reinforced concrete wall dimensions and concrete strengths.

\begin{tabular}{cccccccc}
\hline Panel & $\begin{array}{c}\text { Size of panel } \\
H_{w} \times L_{w} \times t_{w}(\mathrm{~mm})\end{array}$ & $\begin{array}{c}H_{o} \times L_{o} \\
(\mathrm{~mm})\end{array}$ & $\begin{array}{c}\eta_{o x} \\
(\mathrm{~mm})\end{array}$ & $\begin{array}{c}\eta_{o y} \\
(\mathrm{~mm})\end{array}$ & $\begin{array}{c}f_{c}^{\prime} \\
(\mathrm{MPa})\end{array}$ & $\begin{array}{c}\text { Slenderness } \\
\text { ratio }\left(H_{w} / t_{w}\right)\end{array}$ & $\begin{array}{c}\text { Aspect ratio } \\
\left(H_{w} / L_{w}\right)\end{array}$ \\
\hline WS1 & $1000 \times 1200 \times 40$ & - & - & - & 58.8 & 25 & 0.83 \\
WL1 & $1000 \times 1200 \times 40$ & $330 \times 360$ & 380 & 500 & 59.2 & 25 & 0.83 \\
WC1 & $1000 \times 1200 \times 40$ & $330 \times 360$ & 600 & 500 & 59.2 & 25 & 0.83 \\
WR1 & $1000 \times 1200 \times 40$ & $330 \times 360$ & 820 & 500 & 59.2 & 25 & 0.83 \\
WS2 & $1200 \times 1000 \times 40$ & - & - & - & 58.8 & 30 & 1.20 \\
WC2a & $1200 \times 1000 \times 40$ & $400 \times 150$ & 500 & 600 & 58.8 & 30 & 1.20 \\
WC2b & $1200 \times 1000 \times 40$ & $400 \times 300$ & 500 & 600 & 58.8 & 30 & 1.20 \\
WL2 & $1200 \times 1000 \times 40$ & $400 \times 300$ & 350 & 500 & 59.2 & 30 & 30 \\
WR2 & $1200 \times 1000 \times 40$ & $400 \times 300$ & 650 & 500 & 59.2 & 30 & 1.20 \\
WD2 & $1200 \times 1000 \times 40$ & $400 \times 300$ & 350 & 400 & 59.2 & 30 \\
WS3 & $1400 \times 1000 \times 40$ & - & - & - & 58.8 & 35 & 1.20 \\
WS4 & $1600 \times 1000 \times 40$ & - & - & - & 58.8 & 35 & 1.40 \\
\hline
\end{tabular}

Table 4. CDP model parameters used for the numerical analyses.

\begin{tabular}{ccccc}
\hline$\psi$ & $\xi$ & $\sigma_{b 0} / \sigma_{c 0}$ & $K_{c}$ & $\mu$ \\
\hline $31^{\mathrm{o}}$ & 0.1 & 1.16 & $2 / 3$ & $10^{-4}$ \\
{$[44-47]$} & {$[43]$} & {$[43]$} & {$[43]$} & {$[43]$} \\
\hline
\end{tabular}


Table 5. Comparison of previous test results and FEM.

\begin{tabular}{ccccc}
\hline \multirow{2}{*}{$\begin{array}{c}\text { Support } \\
\text { condition }\end{array}$} & Panel & $N_{u, E X P}(\mathrm{kN})$ & $\begin{array}{c}N_{u, F E M} \\
(\mathrm{kN})\end{array}$ & $N_{u, F E M}$ \\
\cline { 3 - 5 } & & & & $N_{u, E X P}$ \\
\hline \multirow{5}{*}{ OW } & OWNS4 & 441.5 & 407.9 & 0.92 \\
& OWHS4 & 455.8 & 472.2 & 1.04 \\
& O50W1C1.2 & 309.0 & 355.7 & 1.15 \\
& O50W2C1.6 & 195.7 & 230.9 & 1.18 \\
& ST2 & 804.0 & 568.2 & 0.71 \\
& ST4 & 297.0 & 252.2 & 0.85 \\
\hline \multirow{5}{*}{ TW3S } & TSHO & 809.3 & 767.0 & 0.95 \\
& TSHC & 715.2 & 637.1 & 0.89 \\
& TSHL & 668.1 & 680.7 & 1.02 \\
& TW3S-NF & 450.0 & 441.8 & 0.98 \\
\hline \multirow{5}{*}{ TW4S } & TWNS3 & 1177.2 & 1091.3 & 0.93 \\
& T50W1C1.2 & 750.5 & 771.1 & 1.03 \\
& T50W2C1.6 & 647.5 & 642.0 & 0.99 \\
& I-C & 2363.0 & 2251.1 & 0.95 \\
& I-L & 1180.0 & 1071.0 & 0.91 \\
\hline \multirow{4}{*}{ Standard deviation } & & 0.97 \\
& & Mean
\end{tabular}

Table 6. Location of horizontal cracks and effective heights relation.

\begin{tabular}{cccccccccc}
\hline Panel & $\begin{array}{c}H_{w} \\
(\mathrm{~mm})\end{array}$ & $\begin{array}{c}L_{w} \\
(\mathrm{~mm})\end{array}$ & $\begin{array}{c}H_{c} \\
(\mathrm{~mm})\end{array}$ & $H_{w} / L_{w}$ & $k[12]$ & $k[24]$ & $\begin{array}{c}H_{w e}(\mathrm{~mm}) \\
{[12]}\end{array}$ & $\begin{array}{c}H_{w e}(\mathrm{~mm}) \\
{[24]}\end{array}$ & $\begin{array}{c}2 H_{c} \\
(\mathrm{~mm})\end{array}$ \\
\hline WS1 & 1000 & 1200 & 463.0 & 0.83 & 0.928 & 0.872 & 928.4 & 872.0 & 926.0 \\
WS2 & 1200 & 1000 & 570.0 & 1.20 & 0.862 & 0.777 & 1034.5 & 932.4 & 1140.0 \\
WS3 & 1400 & 1000 & 520.0 & 1.40 & 0.821 & 0.727 & 1149.6 & 1017.8 & 1040.0 \\
WS4 & 1600 & 1000 & 640.0 & 1.60 & 0.779 & 0.679 & 1245.7 & 1086.4 & 1280.0 \\
WL1 & 1000 & 1200 & 490.0 & 0.83 & 0.928 & 0.872 & 928.4 & 872.0 & 980.0 \\
WC1 & 1000 & 1200 & 460.0 & 0.83 & 0.928 & 0.872 & 928.4 & 872.0 & 920.0 \\
WR1 & 1000 & 1200 & 490.0 & 0.83 & 0.928 & 0.872 & 928.4 & 872.0 & 980.0 \\
WC2a & 1200 & 1000 & 585.0 & 1.20 & 0.862 & 0.777 & 1034.5 & 932.4 & 1170.0 \\
WC2b & 1200 & 1000 & 525.0 & 1.20 & 0.862 & 0.777 & 1034.5 & 932.4 & 1050.0 \\
WL2 & 1200 & 1000 & 563.0 & 1.20 & 0.862 & 0.777 & 1034.5 & 932.4 & 1126.0 \\
WR2 & 1200 & 1000 & 575.0 & 1.20 & 0.862 & 0.777 & 1034.5 & 932.4 & 1150.0 \\
WD2 & 1200 & 1000 & 570.0 & 1.20 & 0.862 & 0.777 & 1034.5 & 932.4 & 1140.0 \\
\hline
\end{tabular}


Table 7. Failure loads and predicted loads of test panels by code equations and FEM.

\begin{tabular}{|c|c|c|c|c|c|c|c|c|}
\hline \multirow{2}{*}{ Panel } & \multirow{2}{*}{$N_{u, E X P}(\mathrm{kN})$} & $N_{u, E X P}$ & \multirow{2}{*}{$\begin{array}{c}\text { Eq. (2) } \\
(\mathrm{kN})\end{array}$} & \multirow{2}{*}{$\begin{array}{c}\text { Eq. (3) } \\
(\mathrm{kN})\end{array}$} & \multirow{2}{*}{$\begin{array}{c}N_{u, F E M} \\
(\mathrm{kN})\end{array}$} & \multirow{2}{*}{$\frac{\text { Eq. (2) }}{N_{u, E X P}}$} & \multirow{2}{*}{$\frac{\mathrm{Eq} \cdot(3)}{N_{u, E X P}}$} & \multirow{2}{*}{$\frac{N_{u, F E M}}{N_{u, E X P}}$} \\
\hline & & $f^{\prime}{ }_{c} L_{e f f} t_{w}{ }^{*}$ & & & & & & \\
\hline WS1 & 620.0 & 0.220 & 461.5 & 625.0 & 762.1 & 0.74 & 1.01 & 1.23 \\
\hline WL1 & 529.5 & 0.266 & 323.1 & N/A & 573.4 & 0.61 & $\mathrm{~N} / \mathrm{A}^{\#}$ & 1.08 \\
\hline WC1 & 512.5 & 0.258 & 323.1 & N/A & 526.9 & 0.63 & $\mathrm{~N} / \mathrm{A}^{\#}$ & 1.03 \\
\hline WR1 & 480.5 & 0.242 & 323.1 & N/A & 548.0 & 0.67 & $\mathrm{~N} / \mathrm{A}^{\#}$ & 1.14 \\
\hline WS2 & 500.1 & 0.213 & 224.3 & 373.9 & 589.0 & 0.45 & 0.75 & 1.18 \\
\hline WC2a & 449.0 & 0.225 & 190.7 & N/A & 479.1 & 0.42 & N/A & 1.07 \\
\hline $\mathrm{WC} 2 \mathrm{~b}$ & 414.9 & 0.252 & 157.0 & N/A & 400.6 & 0.38 & $\mathrm{~N} / \mathrm{A}^{\#}$ & 0.97 \\
\hline WL2 & 358.5 & 0.216 & 157.0 & N/A & 393.7 & 0.44 & $\mathrm{~N} / \mathrm{A}^{\#}$ & 1.10 \\
\hline WR2 & 486.7 & 0.294 & 157.0 & N/A & 431.1 & 0.32 & N/A & 0.89 \\
\hline WD2 & 329.8 & 0.211 & 157.0 & N/A & 406.1 & 0.48 & $\mathrm{~N} / \mathrm{A}^{\#}$ & 1.23 \\
\hline WS3 & $392.7^{* *}$ & 0.167 & 50.2 & 196.4 & 555.9 & 0.13 & 0.50 & 1.42 \\
\hline WS4 & 475.7 & 0.202 & $\mathrm{~N} / \mathrm{A}^{\#}$ & 34.1 & 528.3 & N/A & 0.07 & 1.11 \\
\hline \multicolumn{6}{|c|}{ Mean $^{\dagger}$} & 0.51 & 0.61 & 1.09 \\
\hline \multicolumn{6}{|c|}{ Standard deviation $^{\dagger}$} & 0.14 & 0.49 & 0.11 \\
\hline
\end{tabular}

${ }^{*}$ Effective length, $L_{\text {eff }}=L_{w}-L_{o}$

${ }^{* * *}$ The specimen was damaged before testing (premature cracking due to handling)

\# Not applicable due to either the formulae giving negative results which implies zero axial strength or there being no guidelines in standards.

$\dagger$ The WS3 wall was excluded.

Table 8. Comparison of predicted ultimate loads and experimental test results.

\begin{tabular}{|c|c|c|c|c|}
\hline & \multirow{2}{*}{ Panel } & \multirow{2}{*}{$\begin{array}{c}N_{u} \\
(\mathrm{kN})\end{array}$} & \multirow{2}{*}{$\begin{array}{c}\text { Eq. (8) } \\
(\mathrm{kN})\end{array}$} & Eq. (8) \\
\hline & & & & $N_{u}$ \\
\hline \multirow{11}{*}{ Current } & WS1 & 620.0 & 707.1 & 1.14 \\
\hline & WL1 & 529.5 & 525.5 & 0.99 \\
\hline & WC1 & 512.5 & 475.3 & 0.93 \\
\hline & WR1 & 480.5 & 521.2 & 1.08 \\
\hline & WS2 & 500.1 & 653.3 & 1.31 \\
\hline & $\mathrm{WC} 2 \mathrm{a}$ & 449.0 & 536.4 & 1.19 \\
\hline & $\mathrm{WC} 2 \mathrm{~b}$ & 414.9 & 441.8 & 1.06 \\
\hline & WL2 & 358.5 & 437.7 & 1.22 \\
\hline & WR2 & 486.7 & 500.1 & 1.03 \\
\hline & WD2 & 329.8 & 433.8 & 1.32 \\
\hline & WS4 & 475.7 & 486.4 & 1.02 \\
\hline \multirow{4}{*}{ Previous } & TSHO & 809.3 & 809.0 & 1.00 \\
\hline & TSHC & 715.2 & 613.2 & 0.86 \\
\hline & TSHL & 668.1 & 619.9 & 0.93 \\
\hline & TW3S-NF & 450.0 & 420.4 & 0.93 \\
\hline \multirow{2}{*}{\multicolumn{4}{|c|}{$\begin{array}{c}\text { Mean } \\
\text { Standard deviation }\end{array}$}} & 1.07 \\
\hline & & Standard deviation & & 0.14 \\
\hline
\end{tabular}


Table A1. Previously tested panel dimensions, concrete strengths, ultimate loads and axial strength ratios.

\begin{tabular}{|c|c|c|c|c|c|c|c|c|c|}
\hline \multirow{2}{*}{ Ref. } & \multirow{2}{*}{$\begin{array}{l}\text { Support } \\
\text { type }\end{array}$} & \multirow{2}{*}{ Panel } & \multirow{2}{*}{$\begin{array}{c}H_{w} \times L_{w} \times t_{w} \\
(\mathrm{~mm})\end{array}$} & \multicolumn{3}{|c|}{ Opening (unit: mm) } & \multirow{2}{*}{$\begin{array}{c}f_{c}^{\prime} \\
(\mathrm{MPa})\end{array}$} & \multirow{2}{*}{$\begin{array}{c}N_{u} \\
(\mathrm{kN})\end{array}$} & \multirow{2}{*}{$\begin{array}{c}N_{u} l \\
f^{\prime}{ }_{c} L_{e f f} t_{w}{ }^{*}\end{array}$} \\
\hline & & & & $n \times H_{o} \times L_{o}$ & $\eta_{o x}$ & $\eta_{o y}$ & & & \\
\hline \multirow{2}{*}[2]{} & OW & OW-NF & $1200 \times 1200 \times 40$ & $1 \times 450 \times 450$ & 600 & 600 & 54.7 & 273.9 & 0.167 \\
\hline & TW3S & TW3S-NF & $1200 \times 1200 \times 40$ & $1 \times 450 \times 450$ & 600 & 600 & 60.0 & 450.0 & 0.250 \\
\hline \multirow{7}{*}{ [6] } & \multirow{7}{*}{ TW3S } & TSNO & $1200 \times 1200 \times 40$ & - & - & - & 50.1 & 502.2 & 0.209 \\
\hline & & TSHO & $1200 \times 1200 \times 40$ & - & - & - & 80.4 & 809.3 & 0.210 \\
\hline & & TSNC & $1200 \times 1200 \times 40$ & $1 \times 300 \times 300$ & 600 & 600 & 50.1 & 353.2 & 0.196 \\
\hline & & TSNR & $1200 \times 1200 \times 40$ & $1 \times 300 \times 300$ & 600 & 600 & 50.1 & 421.1 & 0.233 \\
\hline & & TSNL & $1200 \times 1200 \times 40$ & $1 \times 300 \times 300$ & 600 & 600 & 50.1 & 257.5 & 0.143 \\
\hline & & TSHC & $1200 \times 1200 \times 40$ & $1 \times 300 \times 300$ & 600 & 600 & 80.4 & 715.2 & 0.247 \\
\hline & & TSHL & $1200 \times 1200 \times 40$ & $1 \times 300 \times 300$ & 600 & 600 & 80.4 & 668.1 & 0.231 \\
\hline \multirow{6}{*}[7]{} & \multirow{6}{*}{ TW3S } & TSHC375 & $1200 \times 1200 \times 40$ & $1 \times 375 \times 375$ & 600 & 600 & 78.5 & 323.1 & 0.125 \\
\hline & & TSHC450 & $1200 \times 1200 \times 40$ & $1 \times 450 \times 450$ & 600 & 600 & 78.5 & 267.5 & 0.114 \\
\hline & & TSHC525 & $1200 \times 1200 \times 40$ & $1 \times 525 \times 525$ & 600 & 600 & 78.5 & 210.7 & 0.099 \\
\hline & & TSHR300 & $1200 \times 1200 \times 40$ & $1 \times 300 \times 600$ & 900 & 600 & 78.5 & 147.0 & 0.078 \\
\hline & & TSHL300 & $1200 \times 1200 \times 40$ & $1 \times 300 \times 600$ & 300 & 600 & 78.5 & 126.6 & 0.067 \\
\hline & & TSHB600 & $1200 \times 1200 \times 40$ & $1 \times 600 \times 300$ & 600 & 900 & 78.5 & 267.5 & 0.095 \\
\hline \multirow{2}{*}[10]{} & \multirow{2}{*}{ OW } & ST2 & $2700 \times 460 \times 100$ & - & - & - & 81.4 & 804.0 & 0.215 \\
\hline & & ST4 & $2700 \times 460 \times 100$ & - & - & - & 81.4 & 297.0 & 0.079 \\
\hline \multirow{2}{*}[26]{} & $\mathrm{OW}$ & WWS(a) & $1500 \times 2000 \times 50$ & - & - & - & 90.0 & 1495.0 & 0.166 \\
\hline & TW4S & WWS(b) & $1500 \times 2000 \times 50$ & - & - & - & 72.0 & 2200.0 & 0.306 \\
\hline \multirow{7}{*}[27]{} & \multirow{4}{*}{ OW } & OWNS2 & $1200 \times 1200 \times 40$ & - & - & - & 35.7 & 253.0 & 0.148 \\
\hline & & OWHS2 & $1200 \times 1200 \times 40$ & - & - & - & 78.2 & 483.0 & 0.129 \\
\hline & & OWNS4 & $1600 \times 1600 \times 40$ & - & - & - & 51.0 & 441.5 & 0.135 \\
\hline & & OWHS4 & $1600 \times 1600 \times 40$ & - & - & - & 75.9 & 455.8 & 0.094 \\
\hline & \multirow{3}{*}{ TW4S } & TWNS2 & $1200 \times 1200 \times 40$ & - & - & - & 37.0 & 735.8 & 0.414 \\
\hline & & TWHS2 & $1200 \times 1200 \times 40$ & - & - & - & 64.8 & 1177.2 & 0.378 \\
\hline & & TWNS3 & $1400 \times 1400 \times 40$ & - & - & - & 51.0 & 1177.2 & 0.412 \\
\hline \multirow{8}{*}{ [29] } & \multirow{6}{*}{ OW } & O50W1C1.2 & $1200 \times 1200 \times 40$ & $1 \times 300 \times 300$ & 600 & 600 & 53.0 & 309.0 & 0.162 \\
\hline & & O90W1C1.2 & $1200 \times 1200 \times 40$ & $1 \times 300 \times 300$ & 600 & 600 & 95.1 & 470.9 & 0.138 \\
\hline & & O50W1C1.2 & $1200 \times 1200 \times 40$ & $1 \times 300 \times 300$ & 600 & 600 & 53.0 & 309.0 & 0.162 \\
\hline & & O50W2C1.6 & $1600 \times 1600 \times 40$ & $2 \times 400 \times 400$ & $\begin{array}{c}467 \\
1133\end{array}$ & 800 & 51.1 & 195.7 & 0.120 \\
\hline & & O65D1C1.2 & $1200 \times 1200 \times 40$ & $1 \times 750 \times 300$ & 600 & 825 & 60.3 & 243.7 & 0.112 \\
\hline & & O65D1L1.2 & $1200 \times 1200 \times 40$ & $1 \times 750 \times 300$ & 350 & 825 & 60.3 & 206.0 & 0.095 \\
\hline & \multirow[b]{2}{*}{ TW4S } & T50W1C1.2 & $1200 \times 1200 \times 40$ & $1 \times 300 \times 300$ & 600 & 600 & 50.3 & 750.5 & 0.414 \\
\hline & & T50W2C1.6 & $1600 \times 1600 \times 40$ & $2 \times 400 \times 400$ & $\begin{array}{c}467 \\
1133 \\
\end{array}$ & 800 & 50.3 & 647.5 & 0.402 \\
\hline \multirow{2}{*}[35]{} & \multirow{2}{*}{ TW4S } & $\mathrm{I}-\mathrm{C}$ & $1350 \times 1800 \times 60$ & - & - & - & 50.2 & 2363.0 & 0.436 \\
\hline & & $\mathrm{I}-\mathrm{L}$ & $1350 \times 1800 \times 60$ & $1 \times 1050 \times 900$ & 900 & 825 & 50.2 & 1180.0 & 0.435 \\
\hline
\end{tabular}

- ${ }^{*}$ Effective length, $L_{\text {eff }}=L_{w}-L_{o}$ 


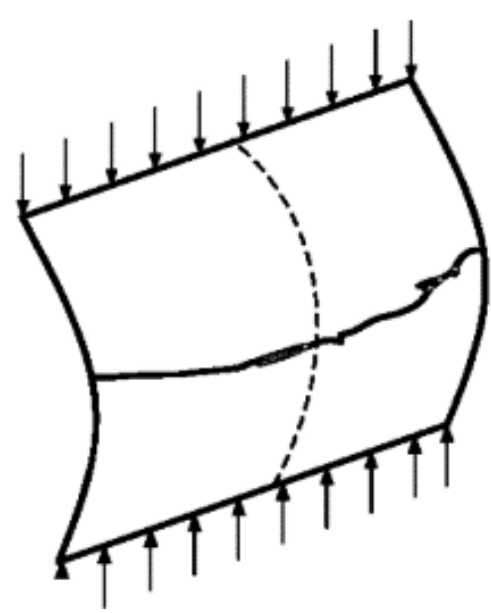

(a) $\mathrm{OW}$

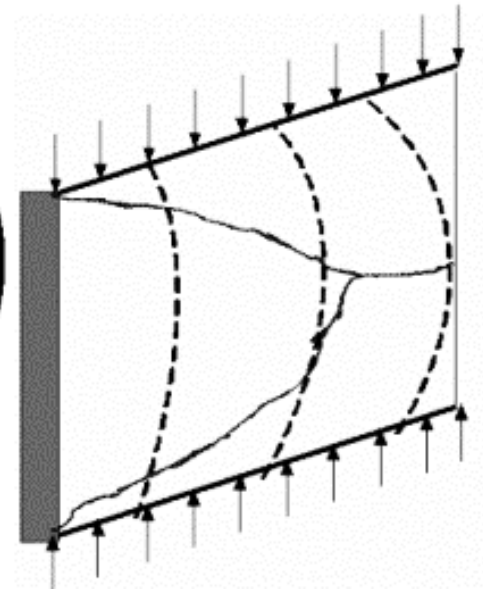

(b) TW3S

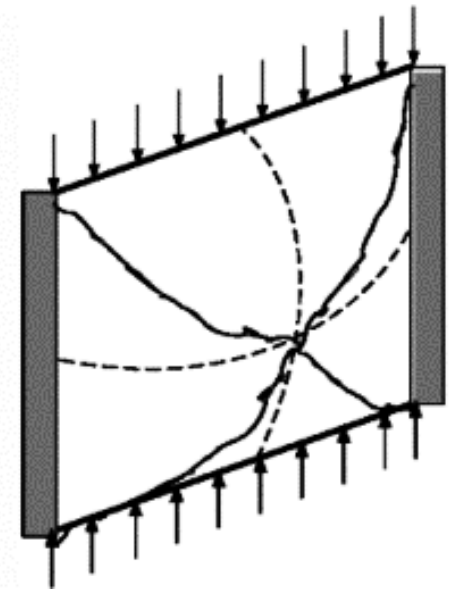

(c) TW4S

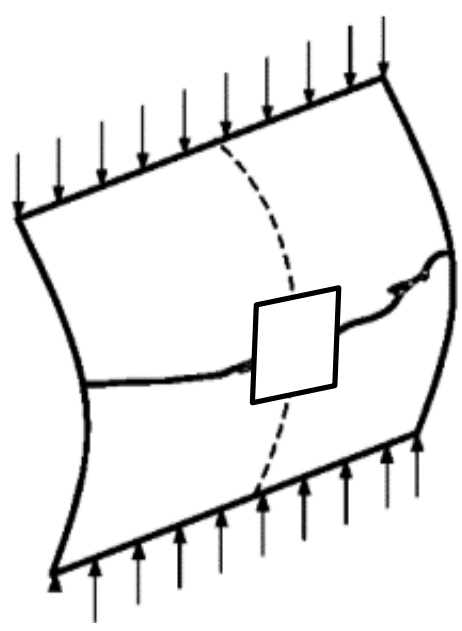

(d) $\mathrm{OW}$

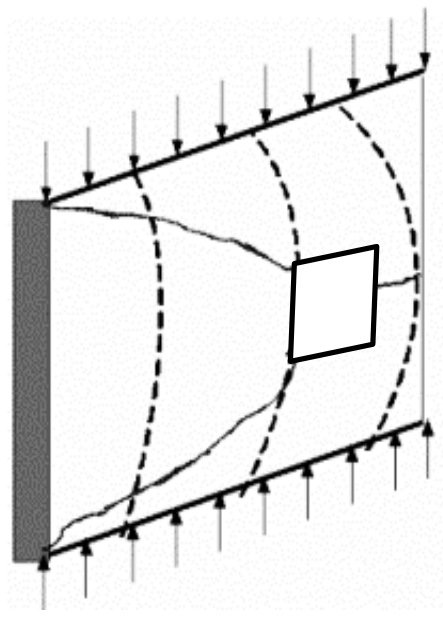

(e) TW3S

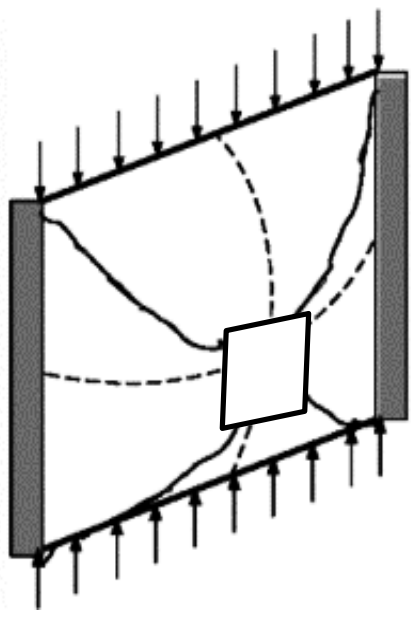

(f) TW4S

$\longrightarrow$ Crack ---- Curvature

Figure 1. Walls with and without openings with various support conditions. 


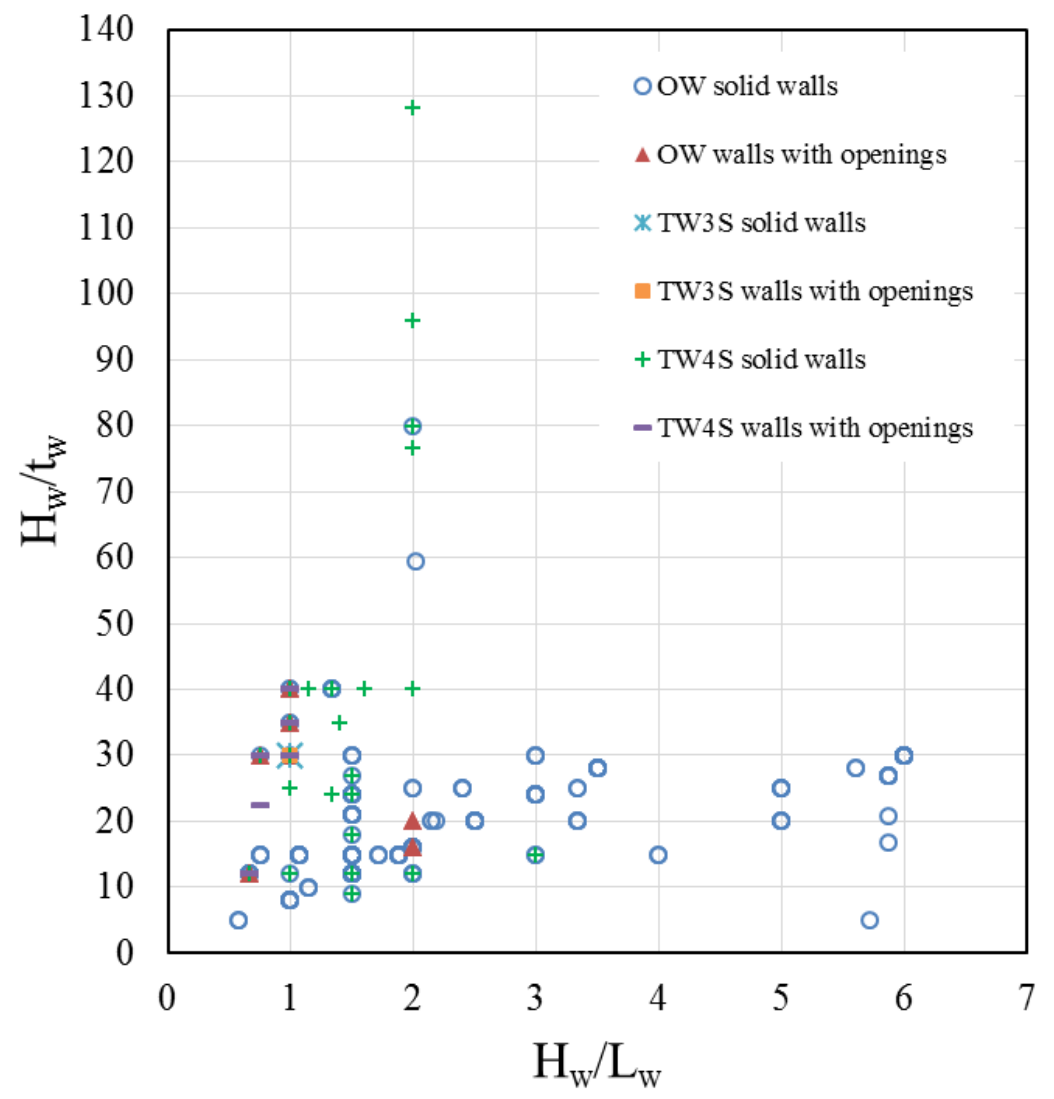

Figure 2. Geometric characteristics of RC walls recorded in the database. 


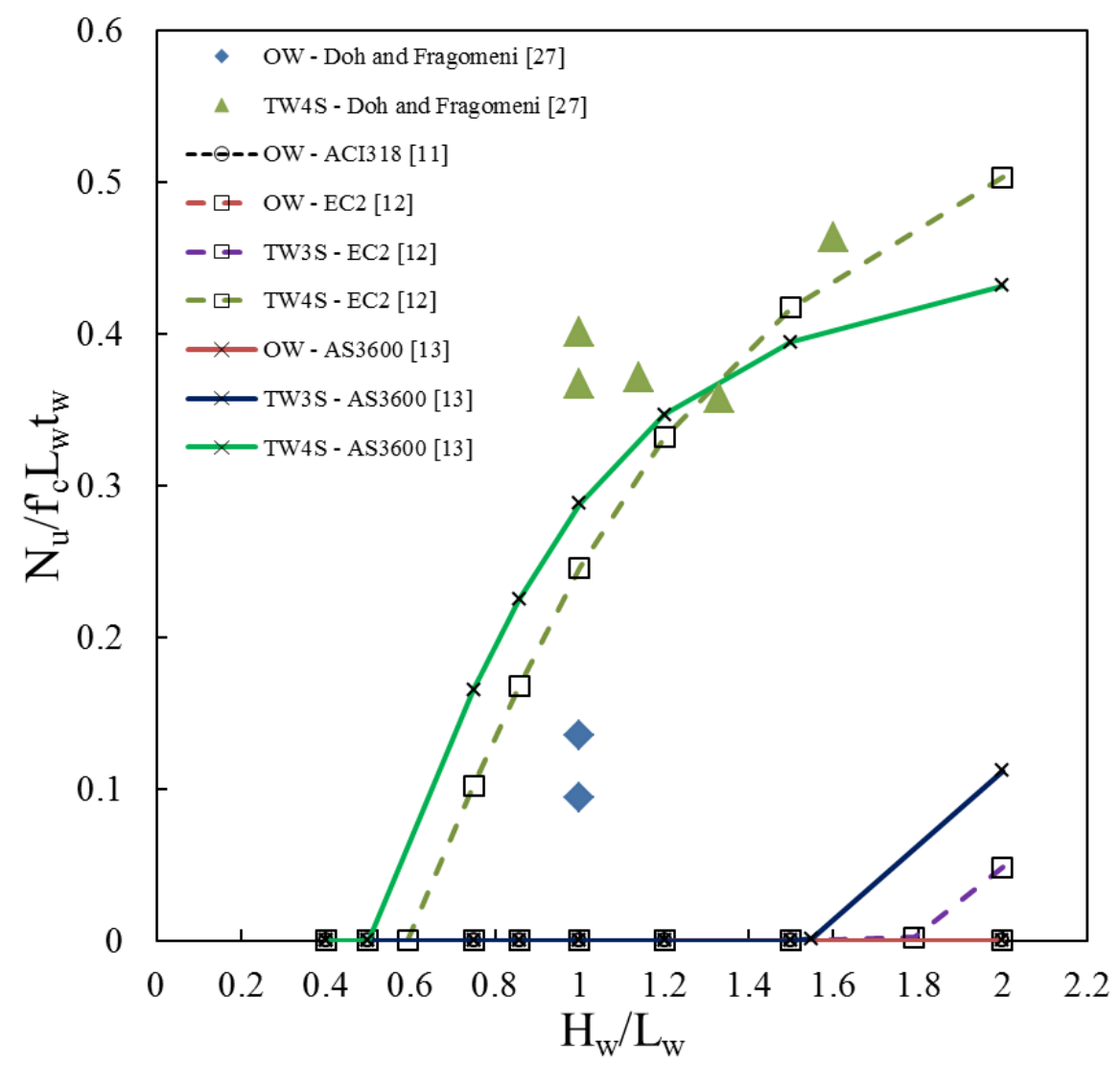

Figure 3. Axial strength ratios versus aspect ratios for walls with different support conditions of $H_{w} / t_{w}=$ 40 and $e=t_{w} / 6$. 


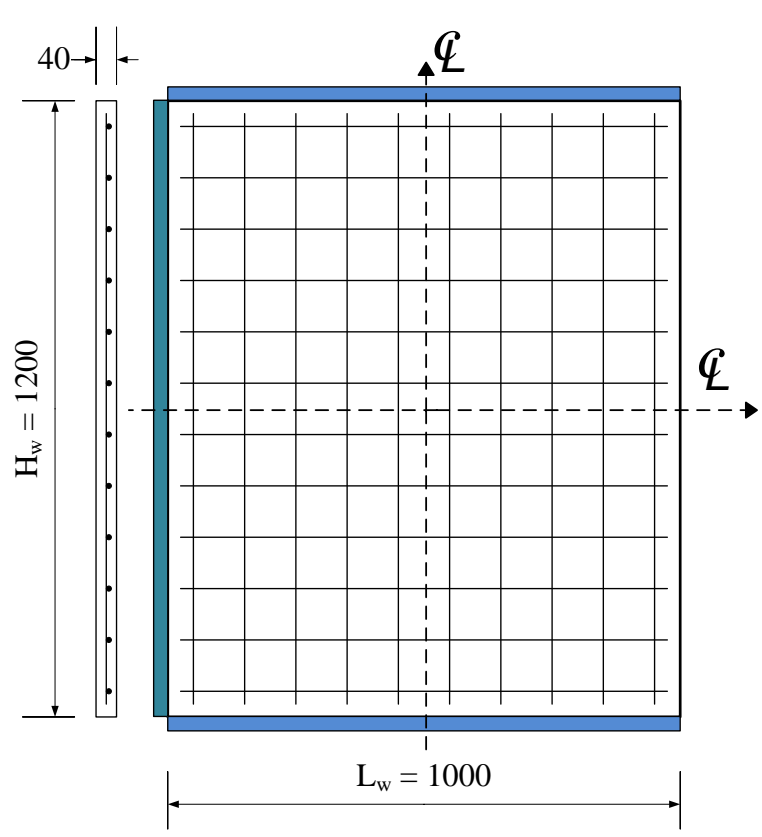

(a) WS2

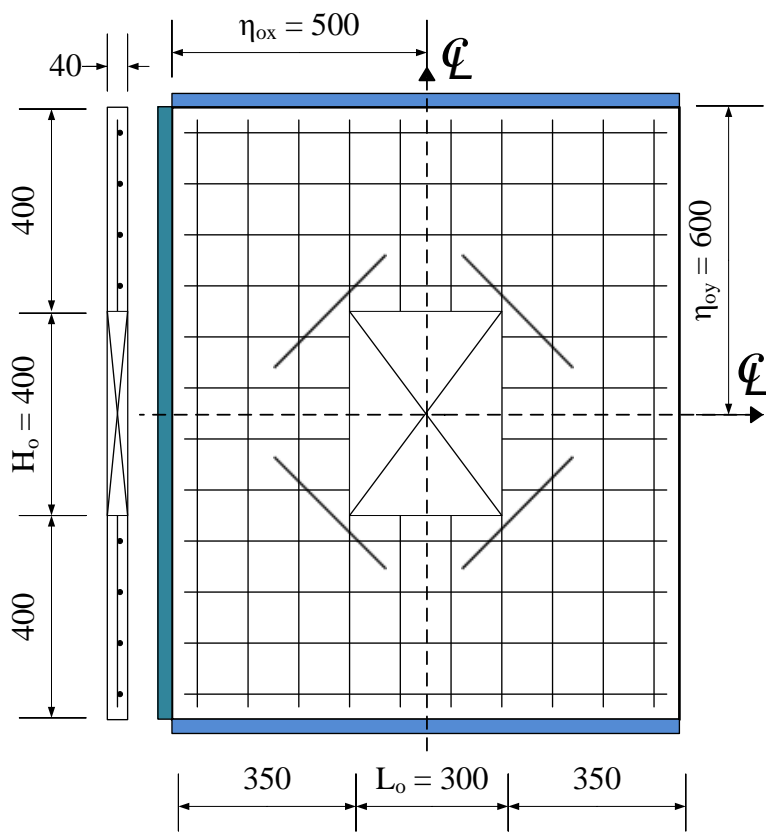

(b) WC2b

Figure 4. Typical wall panels dimensions (dimensions in $\mathrm{mm}$ ).

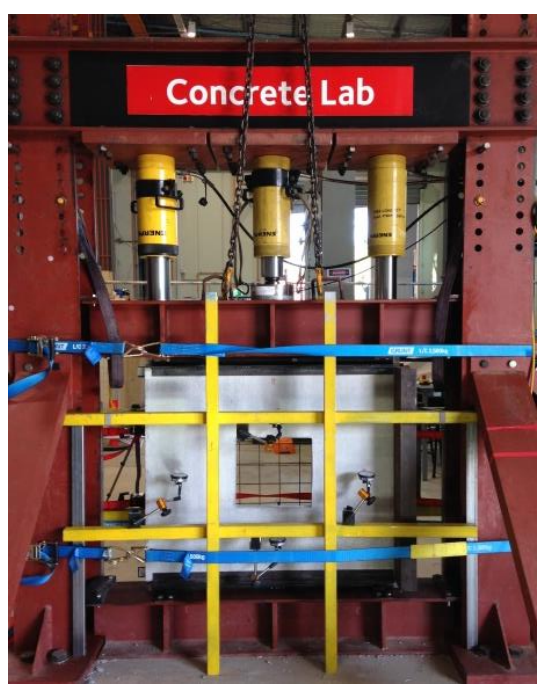

(a) Test frame arrangement

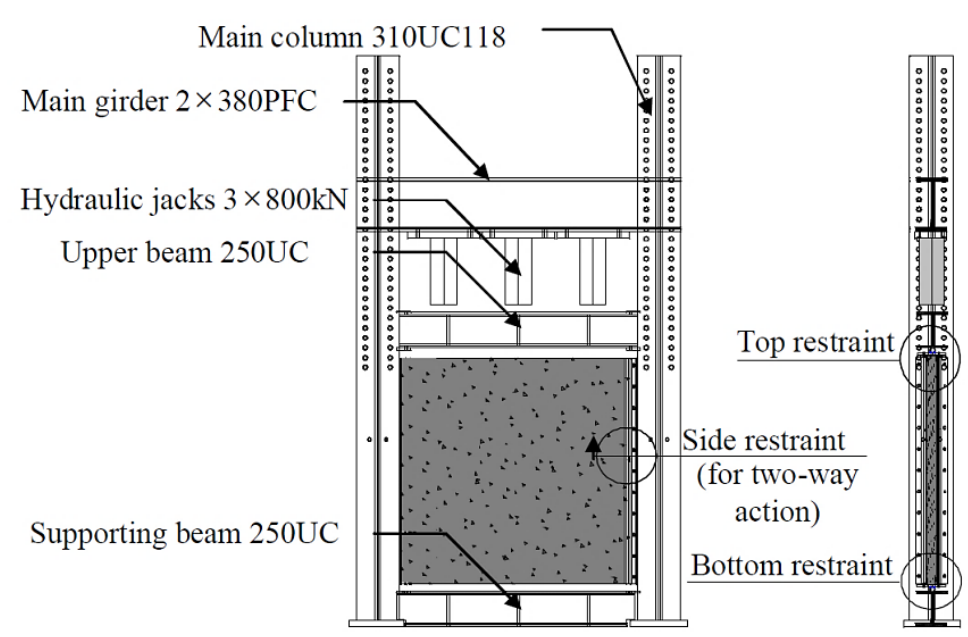

Elevation

Section

(b) Schematic view of test set-up 


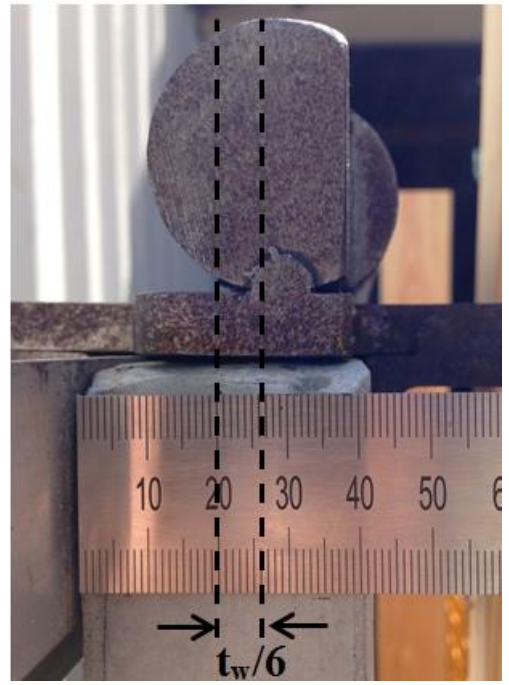

(c) Top restraint

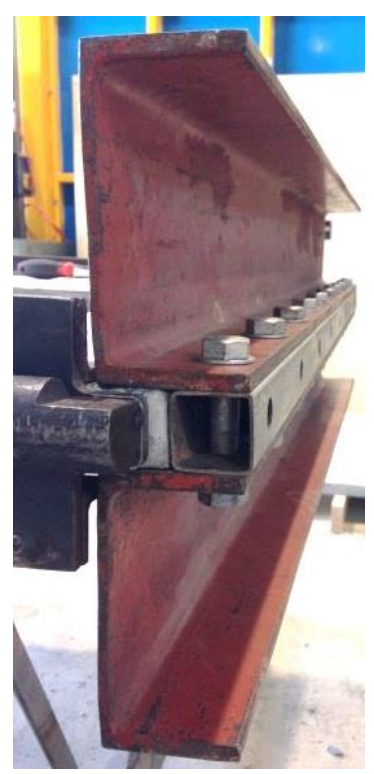

(e) Side restraint

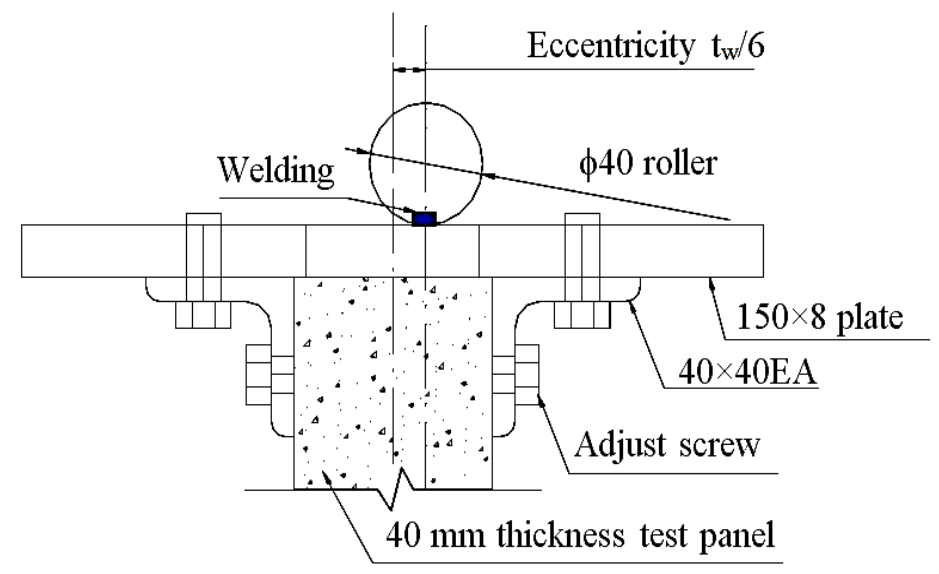

(d) Schematic view of top restraint

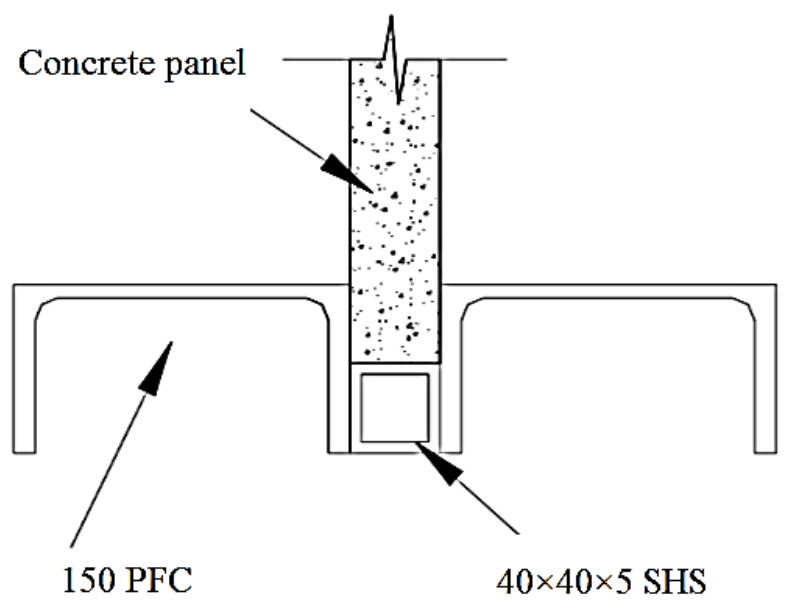

(f) Schematic view of side restraint

Figure 5. Loading frame and support conditions. 


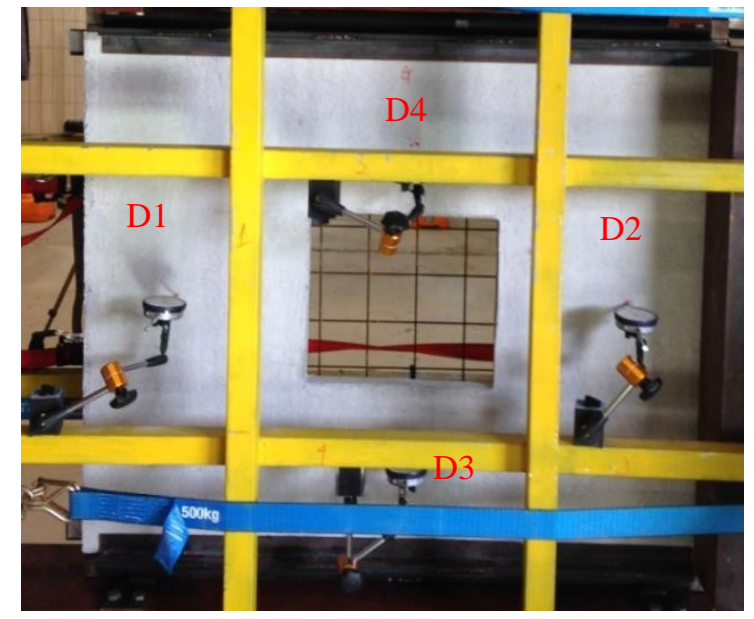

(a) Opening located at the centre of the panel
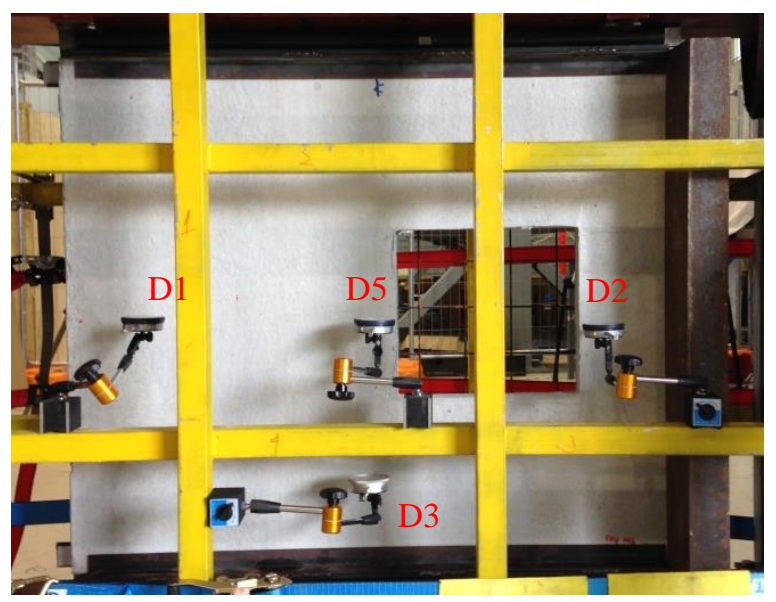

(b) Opening located unsymmetrically

Figure 6. Dial gauge locations on compression face.

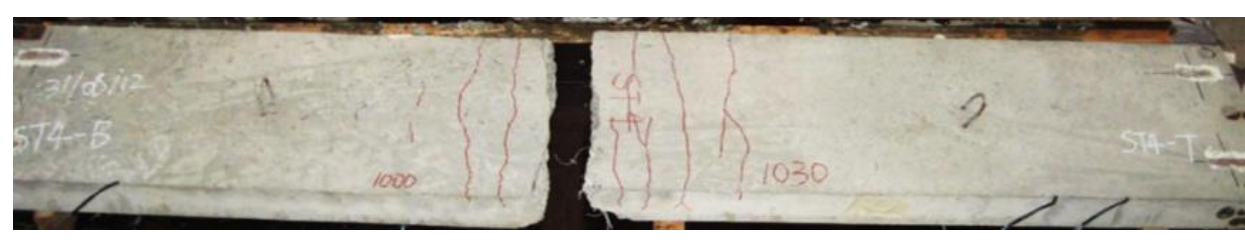

Experiment [10]

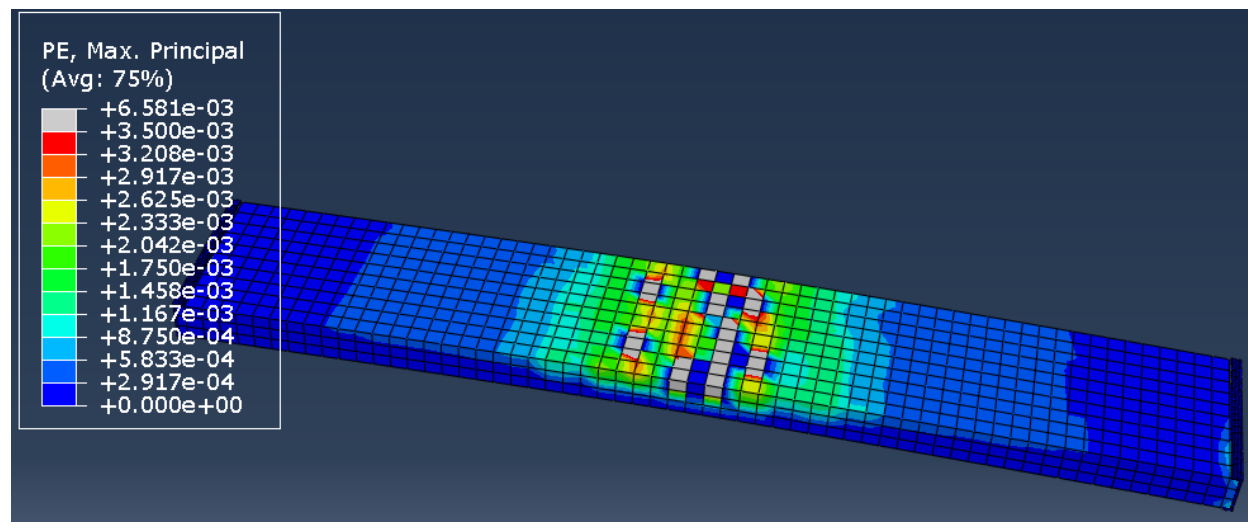

FEM maximum PE

(a) ST4 


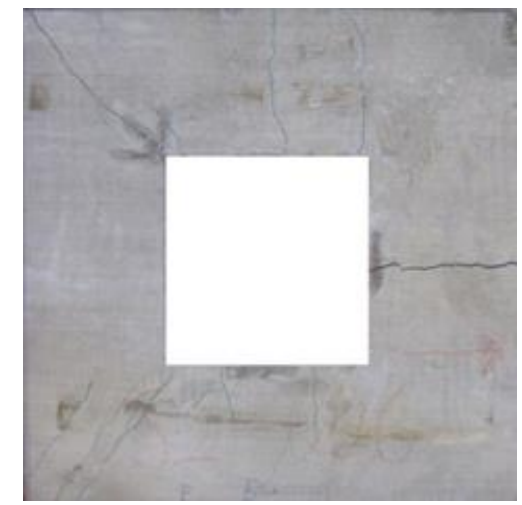

Experiment [2]

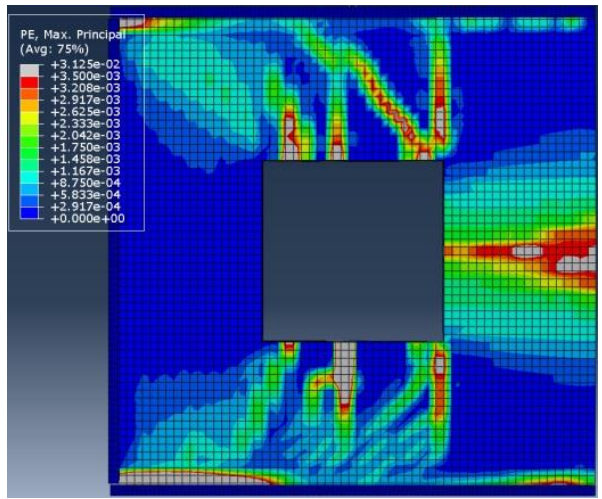

FEM maximum PE

(b) TW3S-NF

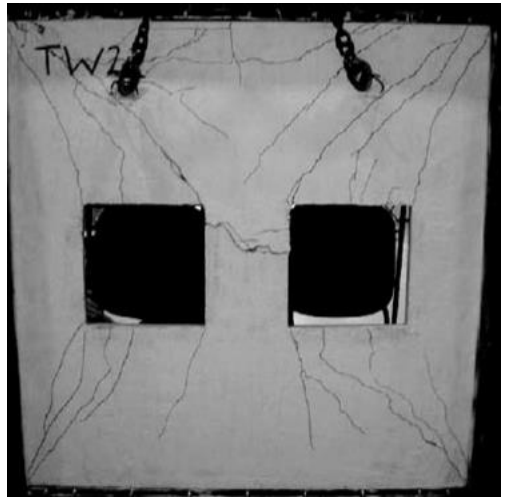

Experiment [29]

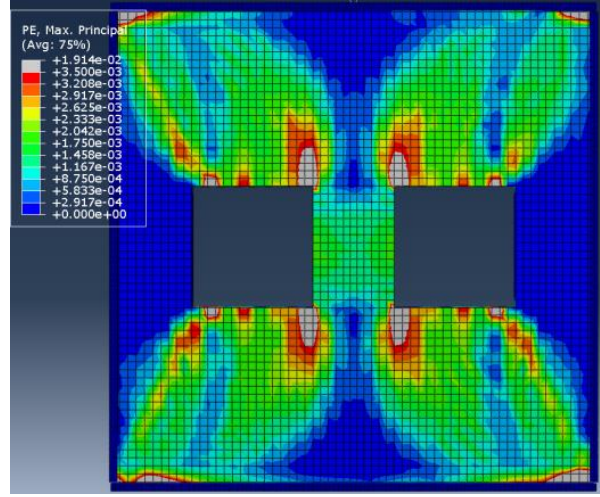

FEM maximum PE

(c) T50W2C1.6

Figure 7. Crack pattern of experiment and correlated maximum PE in FEM for previously tested specimens $[2,10,29]$.

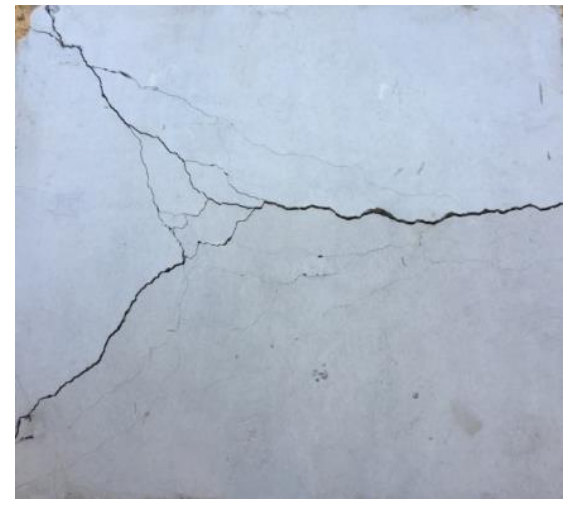

Experiment

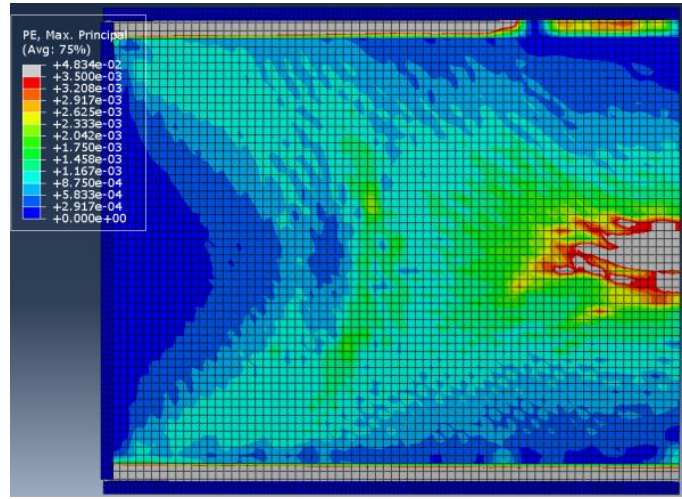

FEM maximum PE

(a) WS1 


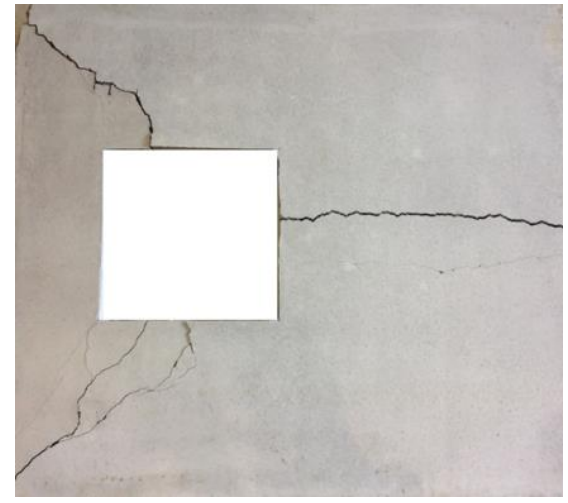

Experiment

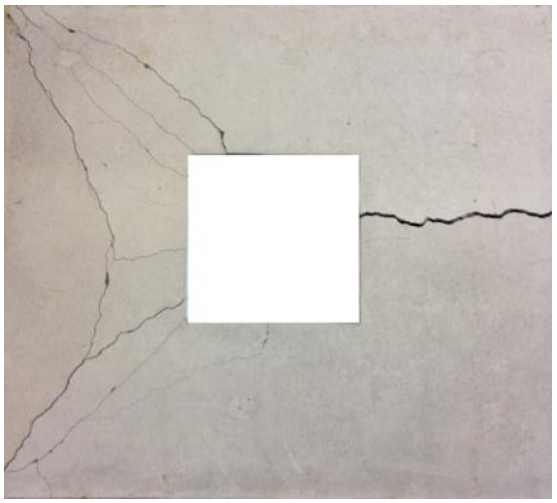

Experiment

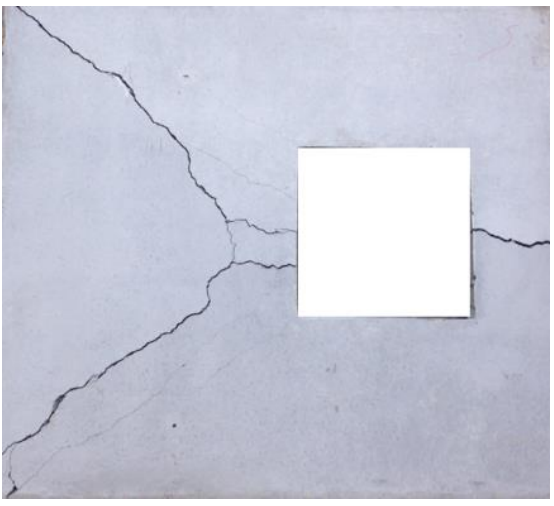

Experiment

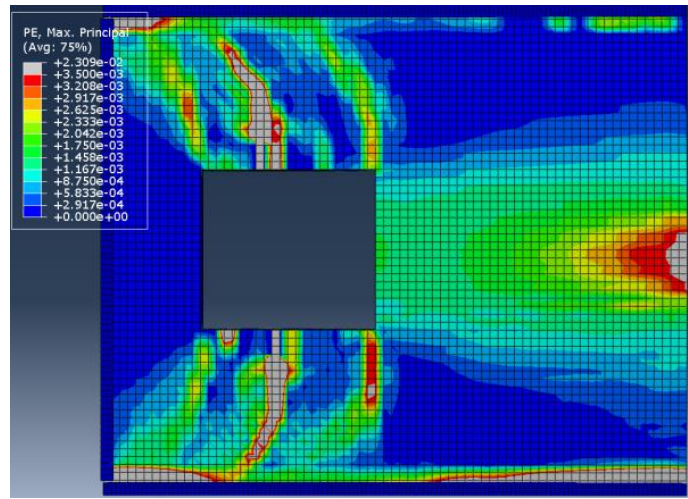

FEM maximum PE

(b) WL1

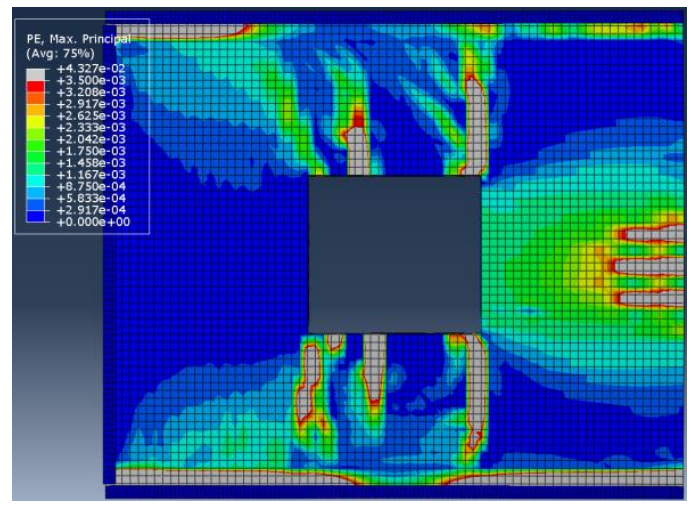

FEM maximum PE

(c) WC1

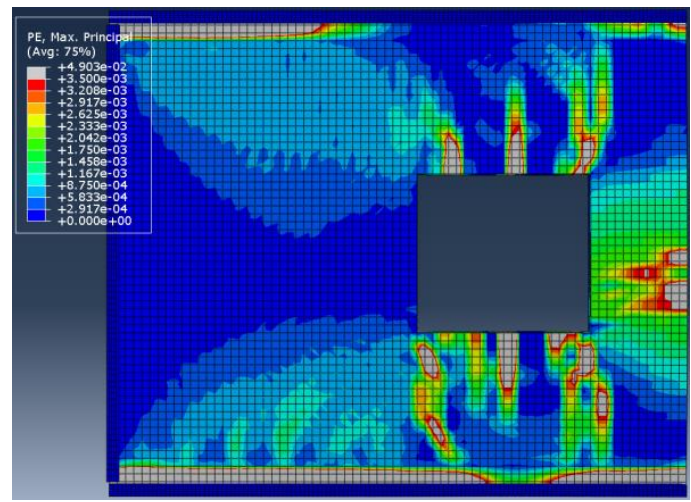

FEM maximum PE

(d) WR1 


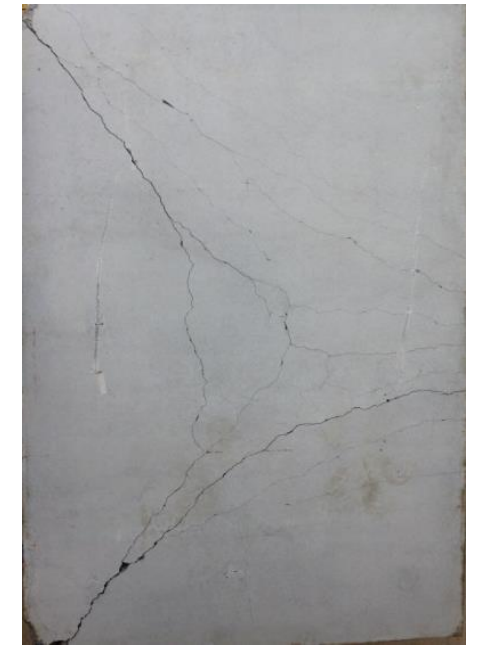

Experiment

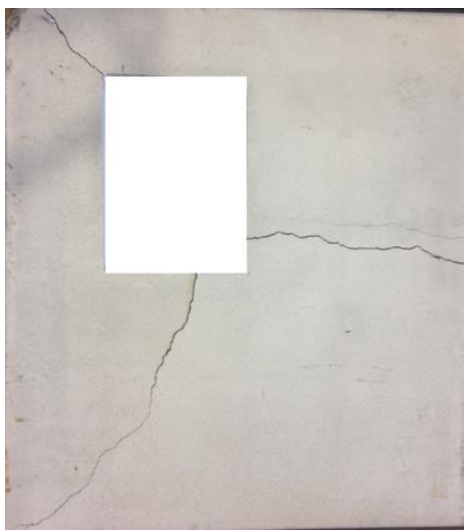

Experiment

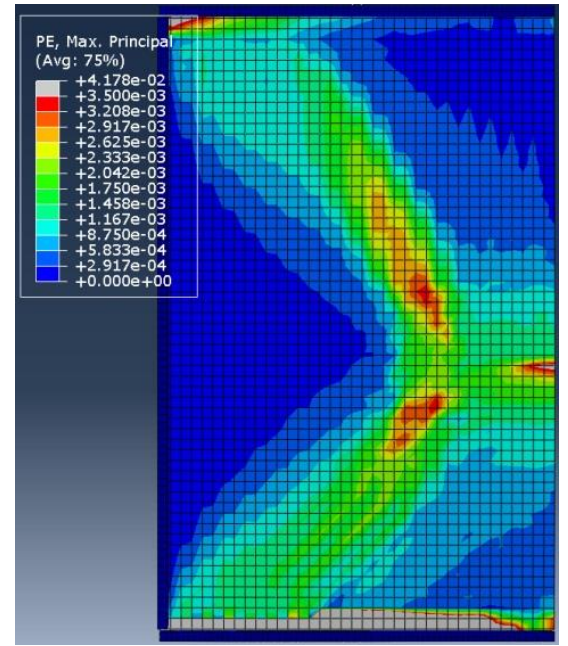

FEM maximum PE

(e) WS4

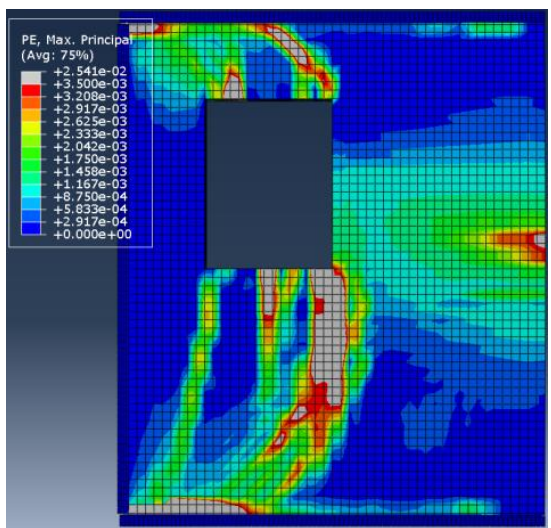

FEM maximum PE

(f) WD2

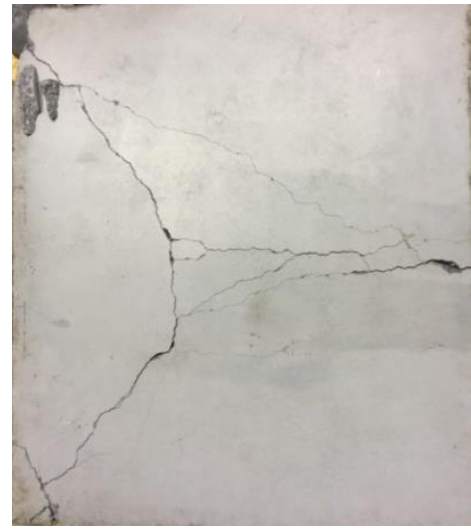

(g) WS2

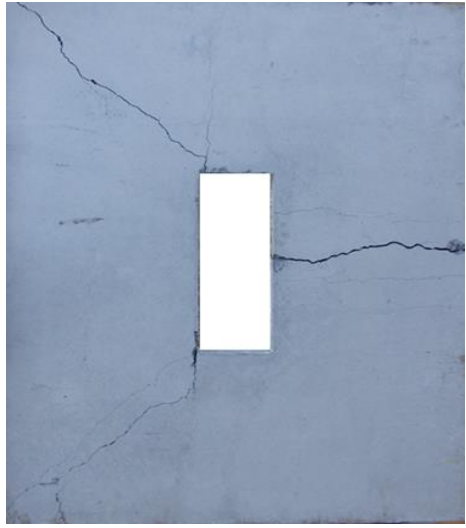

(h) WC2a

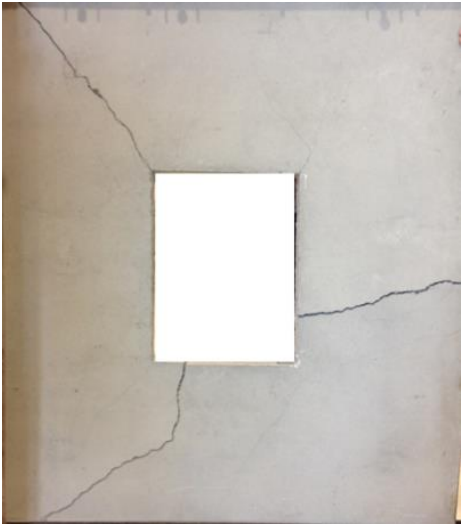

(i) $\mathrm{WC} 2 \mathrm{~b}$ 


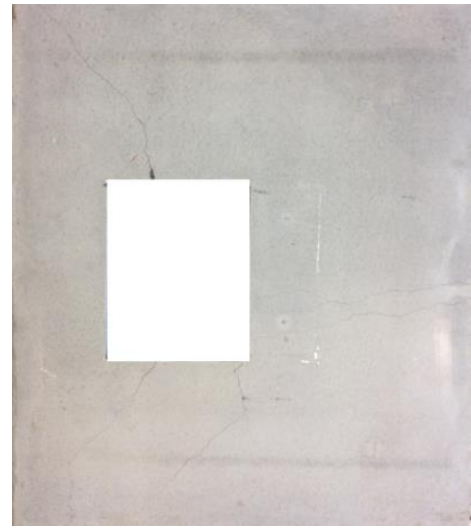

(j) WL2

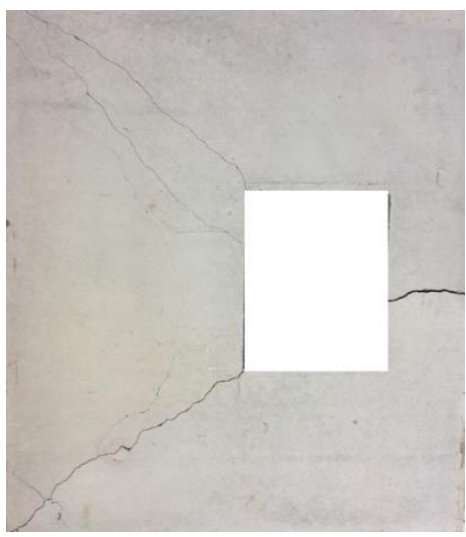

(k) WR2

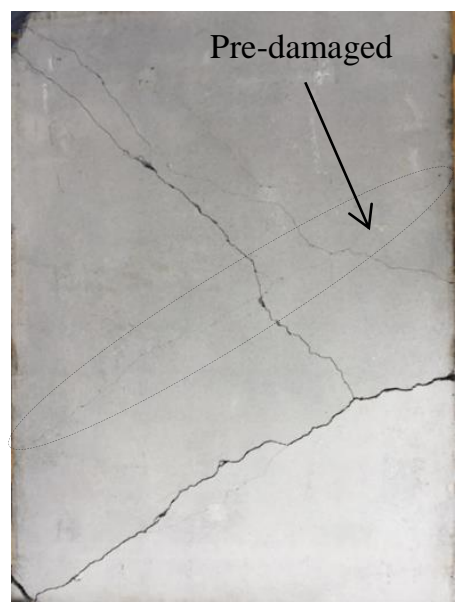

(1) WS3

Figure 8. Crack pattern of current experiment and correlated maximum PE in FEM.

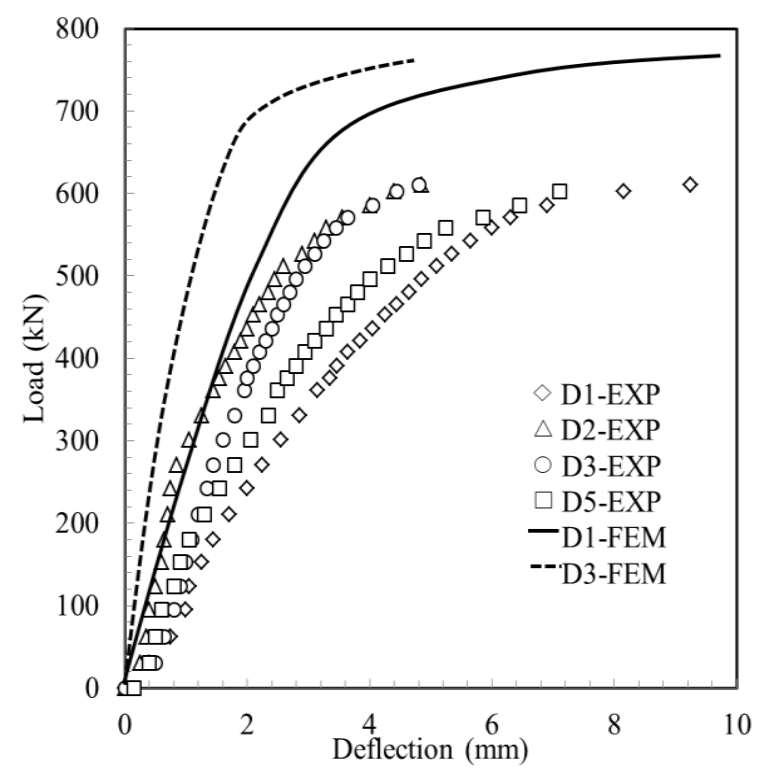

(a) WS1

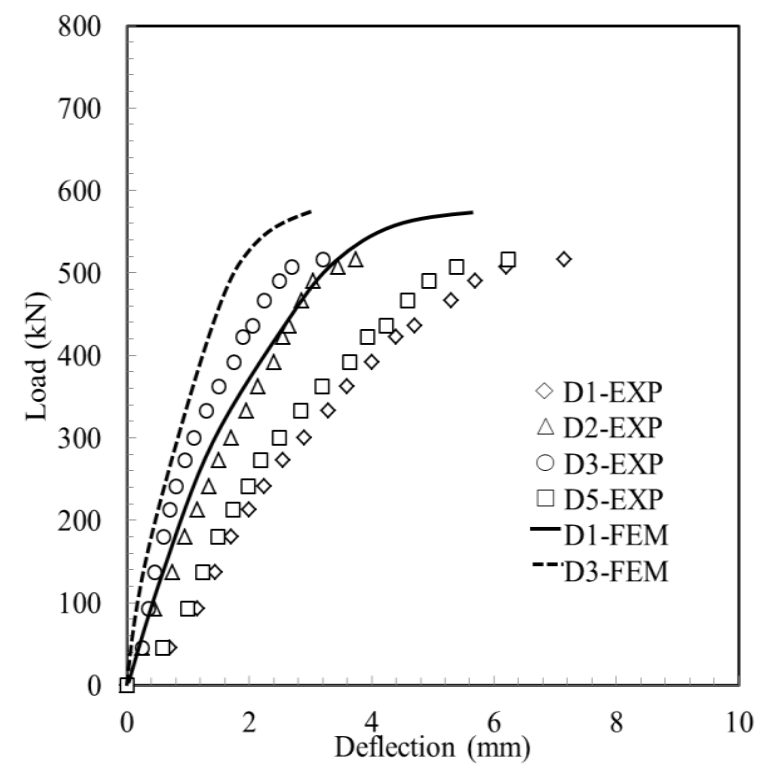

(b) WL1 


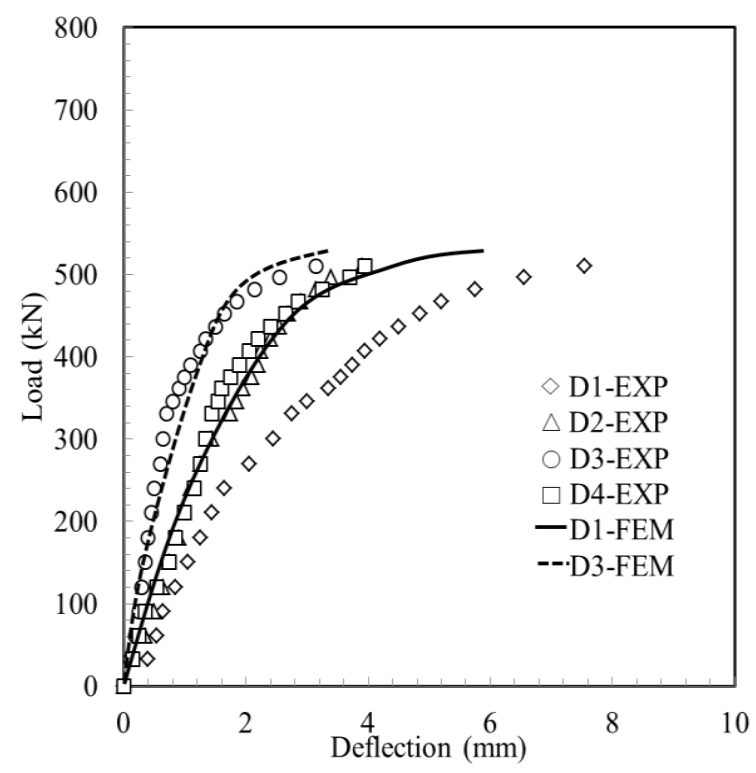

(c) WC1

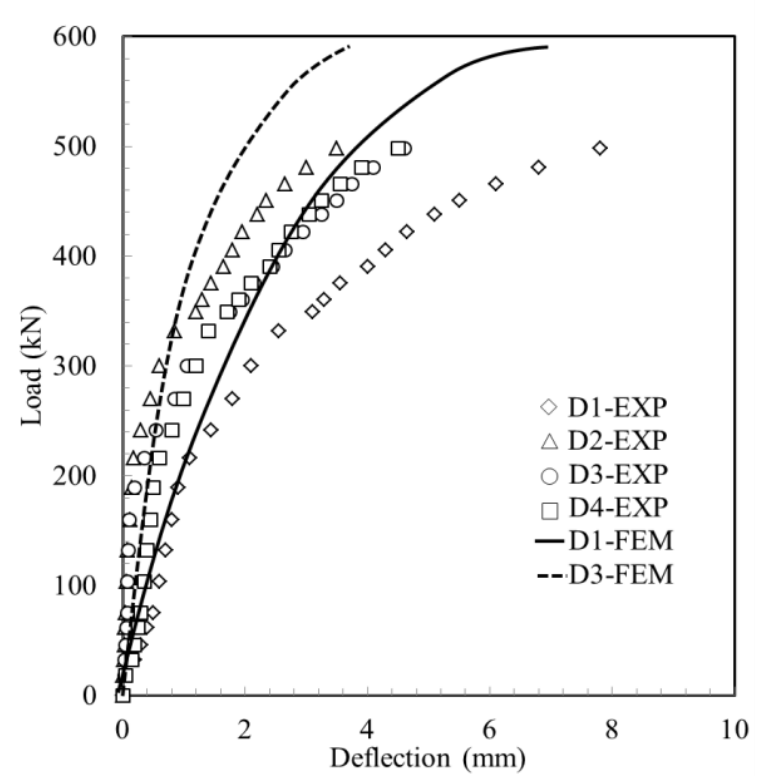

(e) WS2

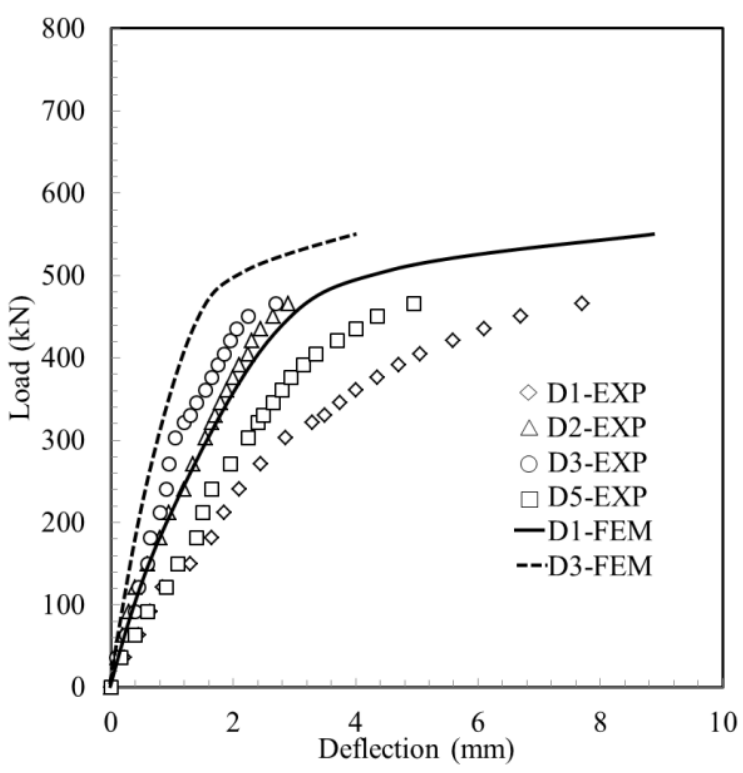

(d) WR1

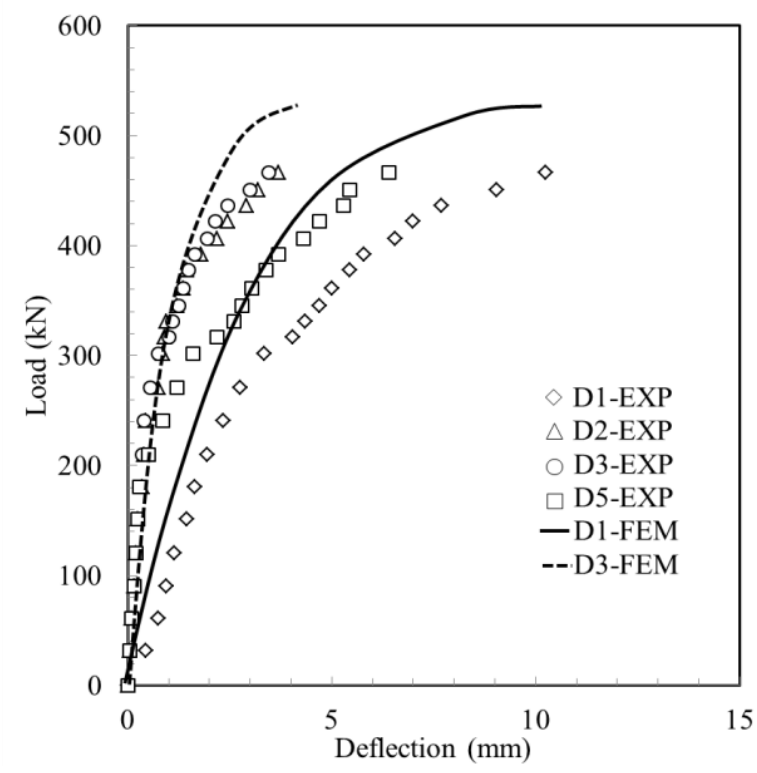

(f) WS4

Figure 9. Load versus lateral deflection curves. 


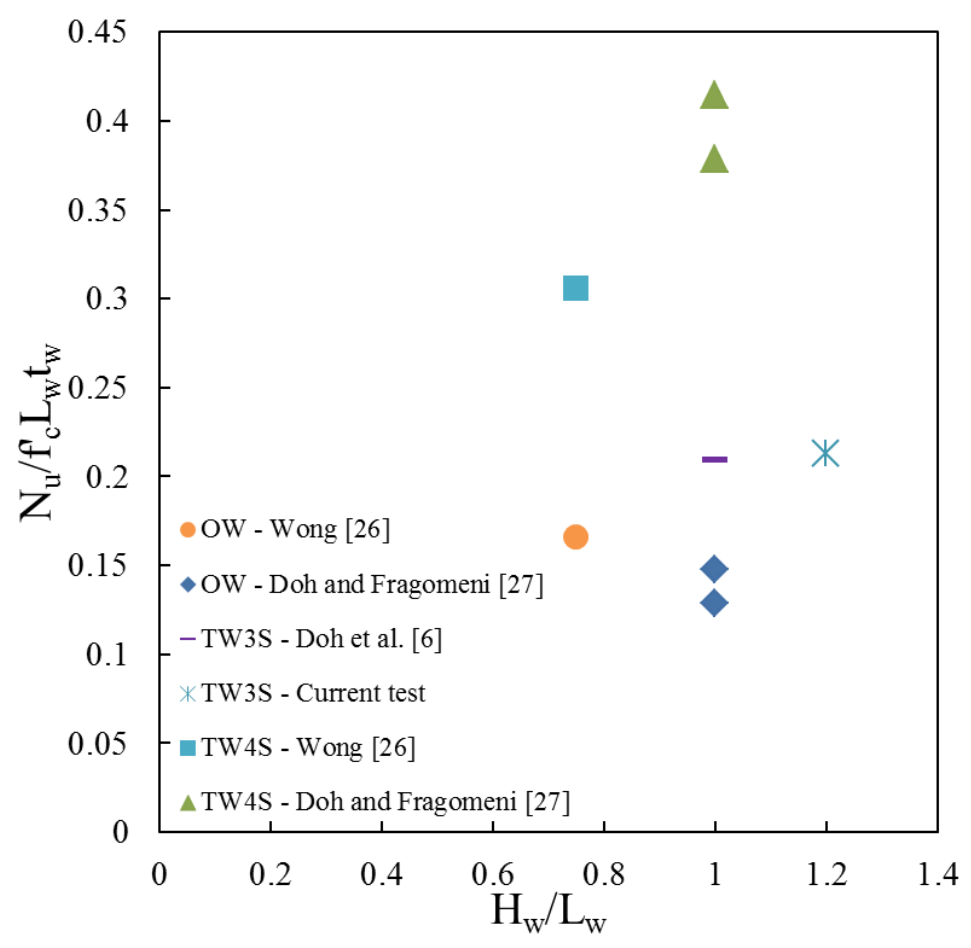

(a) Experimental results

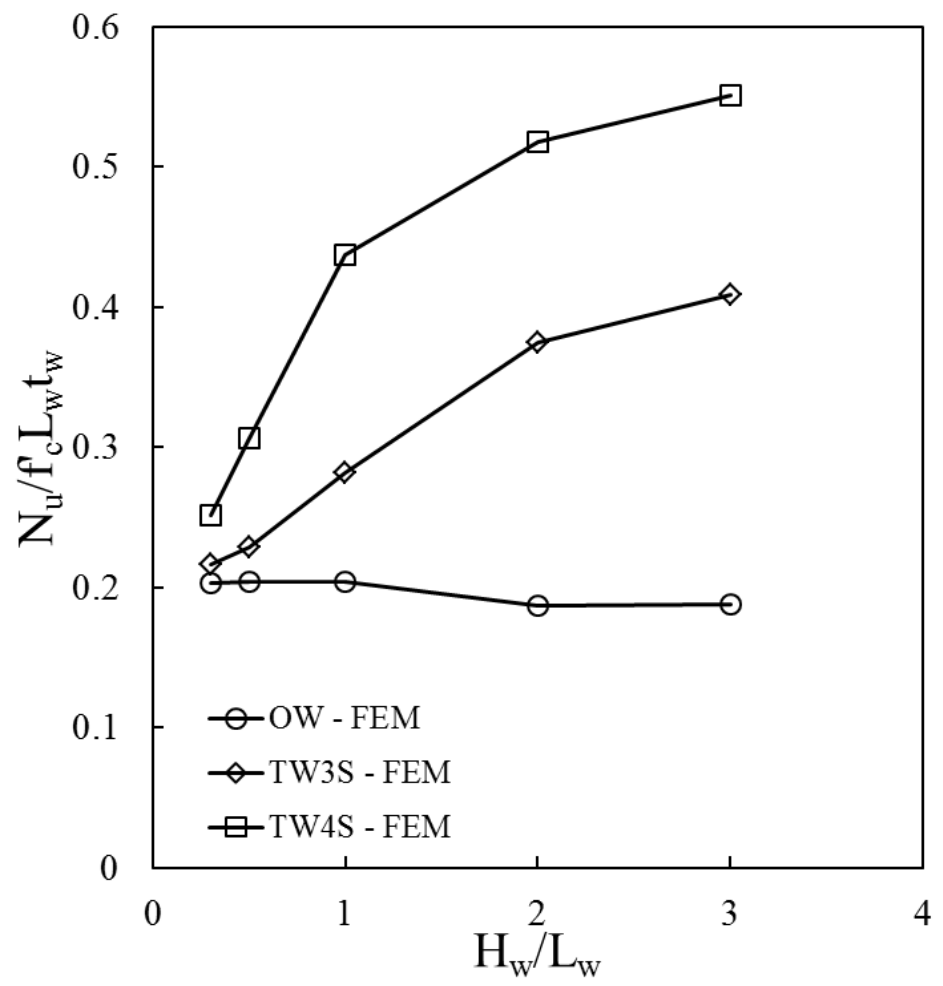

(b) FEM results

Figure 10. Axial strength ratio verus aspect ratio for walls of $H_{w} / t_{w}=30$ with different support conditions. 


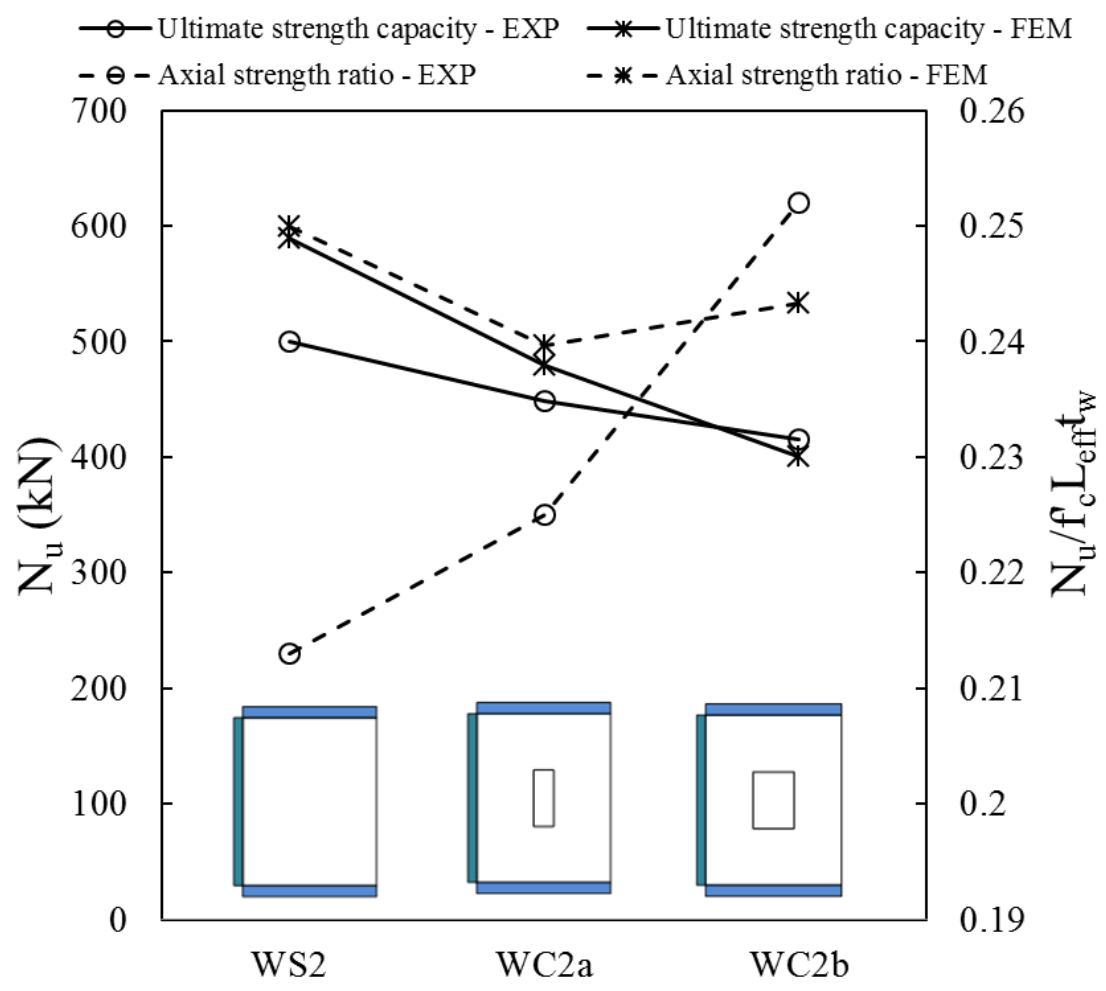

Figure 11. Ultimate loads and axial strength ratios of panels with $H_{w} / t_{w}=30, H_{w} / L_{w}=1.20$.

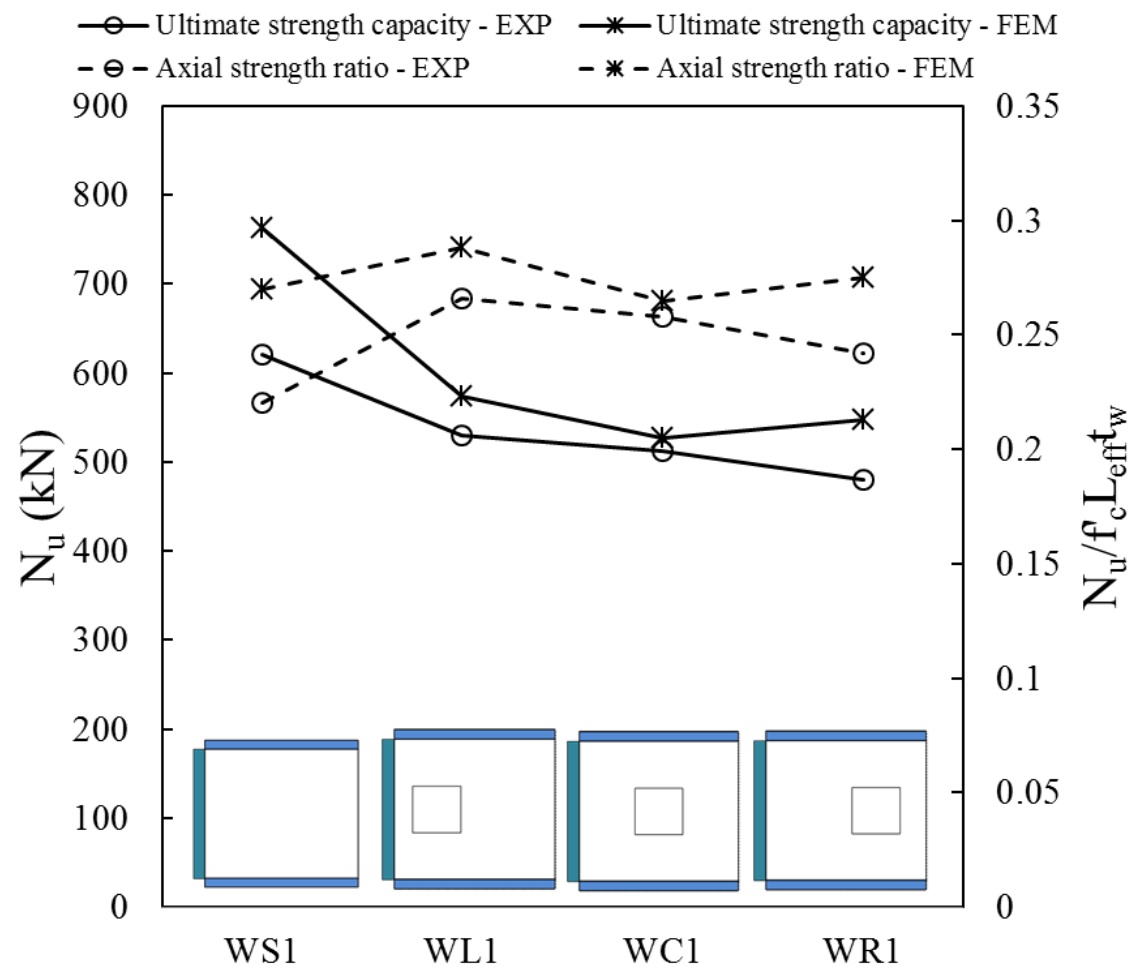

(a) $H_{w} / t_{w}=25, H_{w} / L_{w}=0.83$ 


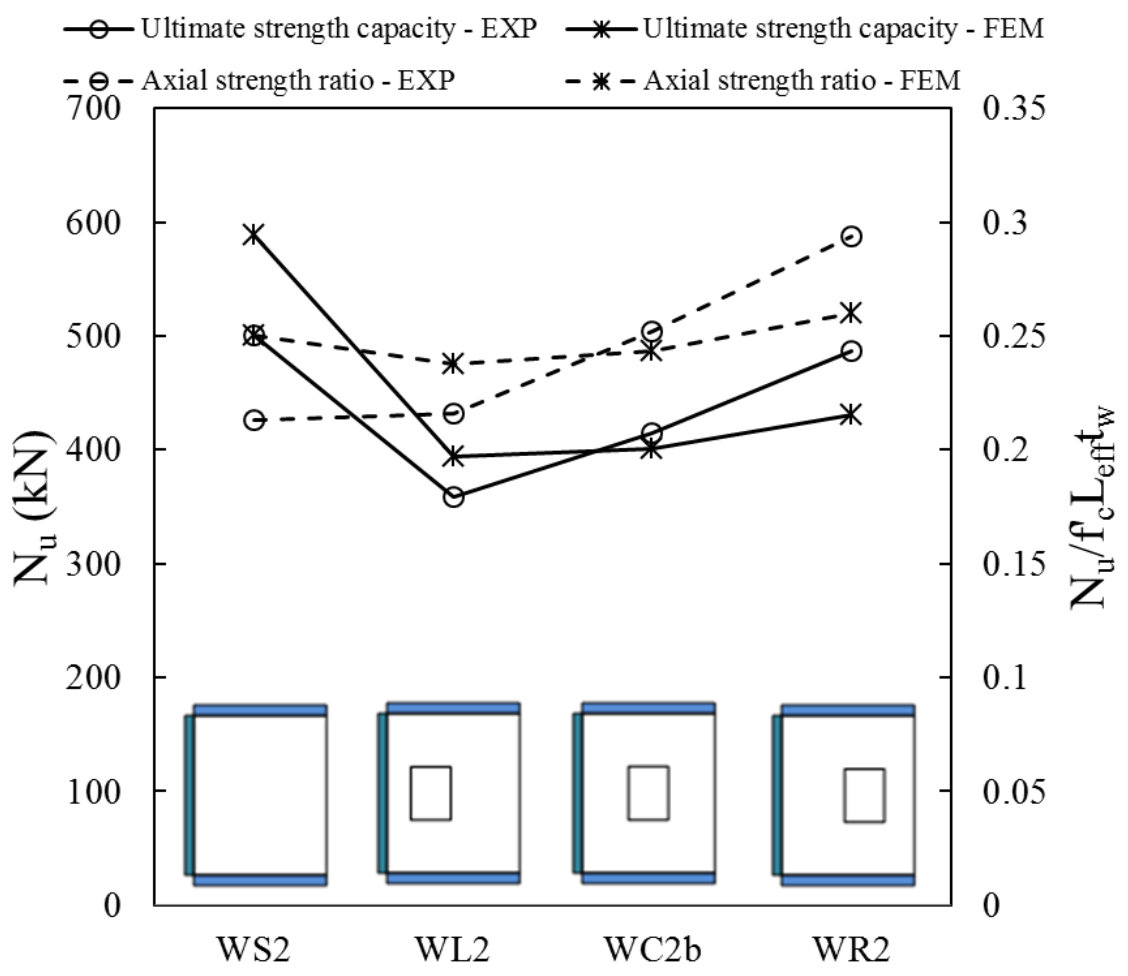

(b) $H_{w} / t_{w}=30, H_{w} / L_{w}=1.20$

Figure 12. Ultimate loads and axial strength ratios of panels.

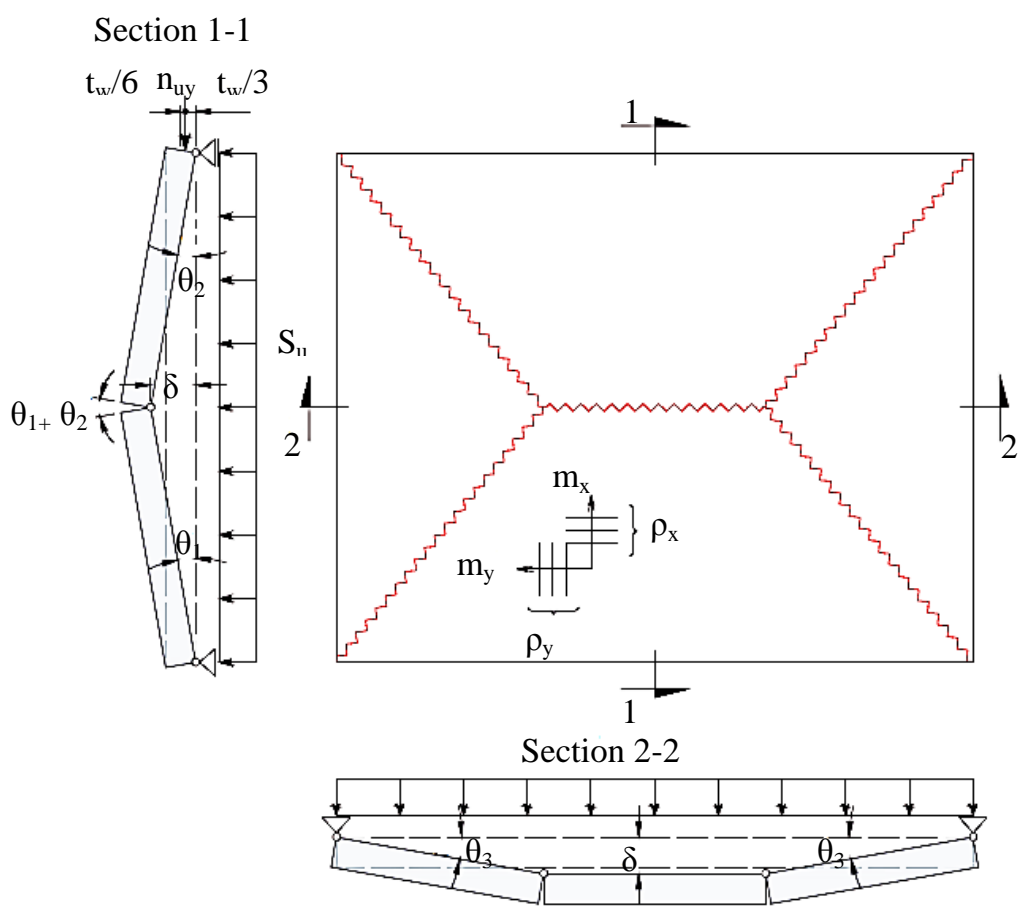

Figure 13. Yield line pattern for a TW4S wall under in-plane and out-of-plane loads [8]. 


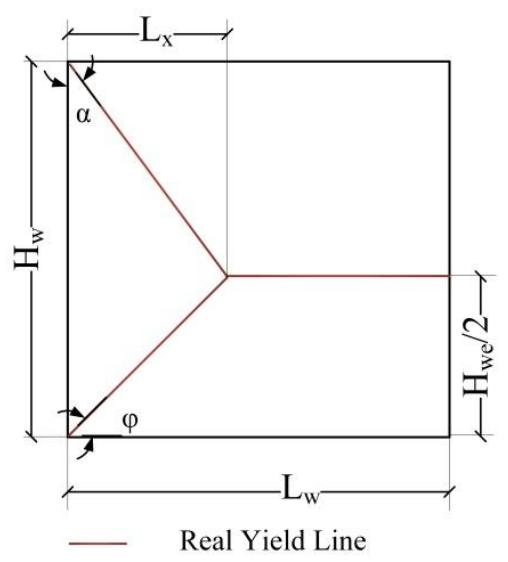

(a) Solid wall

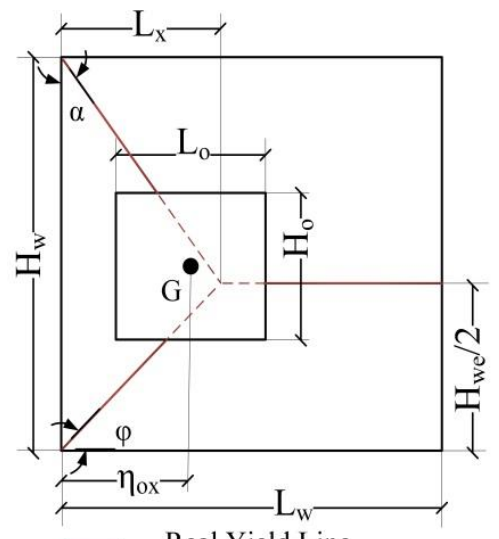

Real Yield Line

- - . Fictitious Yield Line

Pattern 1

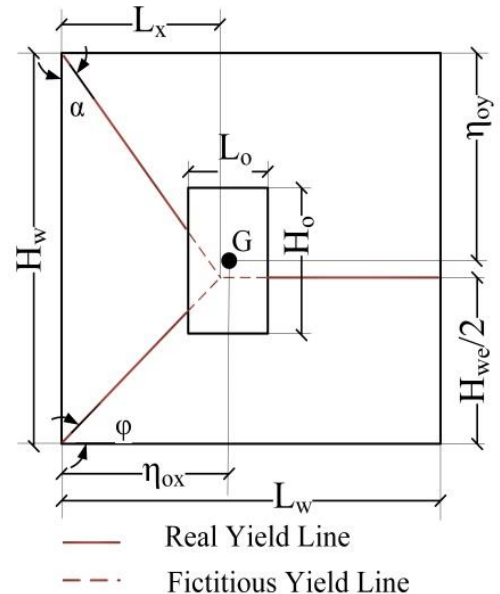

Pattern 3

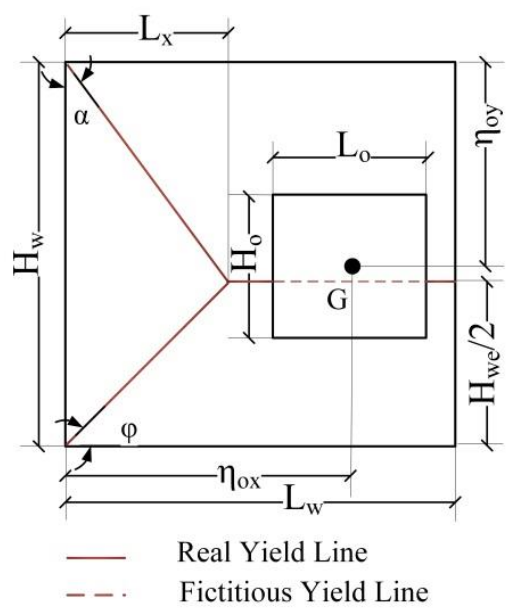

(b) Wall with an opening located outside the region of diagonal yield lines

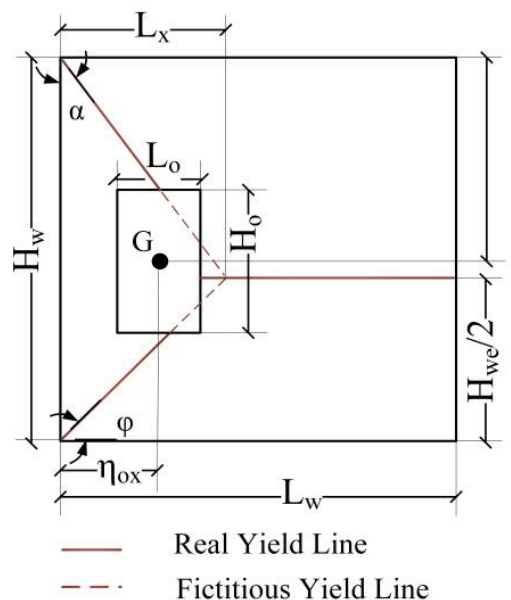

Pattern 2

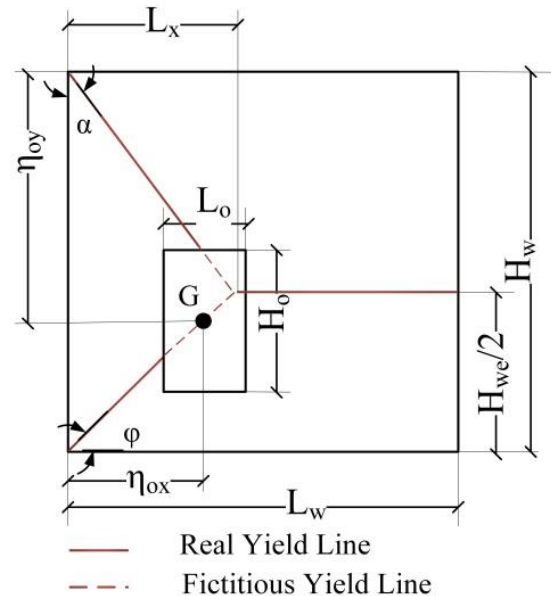

Pattern 4

(c) Wall with an opening located within the region of diagonal yield lines

Figure 14. Proposed yield line pattern for TW3S walls. 